\title{
An approach to enhance efficiency of DEM modelling of soils with crushable grains
}

\author{
M. O. CIANTIA*, M. ARROYO*, F. CALVETti $†$ and A. GENS*
}

\begin{abstract}
In this study oedometric compression tests of hydrocarbon coke, Fontainebleau sand and silica sand are simulated in three dimensions using breakable particles. The method adapts a rigorous breakage criterion for elasto-brittle spheres to represent failure of grains isolated between platens or within granular masses. The breakage criterion allows for the effect of particle bulk and contact properties to be treated separately. A discrete fragmentation multigenerational approach is applied as a spawning procedure. The number of particles quickly increases during the simulation, but is kept manageable by systematic fine exclusion and upscaling. Fine exclusion leads to mass losses between generations, but that loss is accounted for outside the mechanical model. Sensitivity analysis shows that it is enough to keep $53 \%$ of the crushed particle mass within the mechanical model to correctly reproduce experimental macroscopic behaviour. Practical upscaling rules are proposed for $(a)$ contact stiffness, (b) breakage criteria and (c) grain size distribution, and validated simulating the same test, reducing by half the initial number of particles. The results are promising as both the mechanical and grading evolution are well captured with two orders of magnitude savings in computing efficiency.
\end{abstract}

KEYWORDS: discrete-element modelling; particle crushing/crushability; particle-scale behaviour

\section{INTRODUCTION}

Grain fragmentation is significant for several important geotechnical problems, for instance settlement of rockfill dam shoulders (Alonso et al., 2005), side friction on driven piles (Yang et al., 2010), durability of railway ballast and so on. Numerical models of such problems might not be sufficiently accurate if grain fragmentation is ignored. Grain size evolution can be incorporated into continuum constitutive models using suitable formulations (Kikumoto et al., 2010; Zhang et al., 2013), but it can also be modelled using the discrete-element method (DEM).

Grain crushing has been modelled using DEM and employing two alternative approaches. The first is a discrete fragmentation method, a multigenerational approach, in which single elements break and are replaced by a new generation of smaller grains, previously non-existent in the simulation. The second approach does not introduce new particles but instead uses multigrain agglomerates or grain clusters that are susceptible to break into smaller fragments. This latter method, despite allowing a rich description of single grain shape and variability (Cheng et al., 2003; Bolton et al., 2008; Alonso et al., 2012; Cil \& Alshibli, 2012), quickly becomes impractical when the model size grows, as is typical of the large-scale problems of direct engineering application. This has caused increased interest in the multigenerational approach, with several developments, initially in two dimensions (Astrom \& Herrmann, 1998; Tsoungui et al., 1999a; Lobo-Guerrero \& Vallejo, 2005; Ben-Nun \& Einav, 2008; Ben-Nun et al., 2010), and more recently in three dimensions (Marketos \& Bolton, 2009; Bruchmüller et al., 2011; McDowell \& de Bono, 2013).

$\overline{\text { Manuscript received } 11 \text { December 2013; revised manuscript accepted }}$ 13 January 2015.

Discussion on this paper closes on 1 July 2015, for further details see p. ii.

$*$ Departamiento de Ingeniería del Terreno, UPC, Barcelona, Spain.

$\uparrow$ Dipartimento di Ingegneria Civile Ambientale, Politecnico di Milano, Italy.
To apply a multigenerational approach, several further modelling choices are necessary. The most important ones are a particle failure criterion and a particle spawning procedure (Brosh et al., 2011). The particle failure criterion is used to decide when a particle is crushed. Herein a new and versatile particle failure criterion, inspired by the analytical work of Russell \& Muir Wood (2009), is proposed. The particle spawning procedure establishes the relationship between the disappearing broken particle and the new generation of smaller particles (daughters) that replace it, whose size, initial state and properties require specification. One point of debate in this respect has been the issue of mass conservation between generations. Some modellers (BenNun \& Einav, 2010; Brosh et al., 2011; Bruchmüller et al., 2011; McDowell \& de Bono, 2013) enforce strict mass conservation, while others allow partial (Lobo-Guerrero \& Vallejo, 2005) or even total (Couroyer et al., 2000; Marketos \& Bolton, 2009) mass loss when a particle breaks.

Mass conservation between generations is problematic because a new generation of spherical particles does not fit into the volume of the lost particle. Several strategies to alleviate this limitation have been put forward (filling of nearby voids, forced daughter overlapping, time-dependent particle volume increases). These strategies are not without problems: forced overlapping, for instance, results in large repulsive forces between daughters; filling of nearby voids requires a local void search at each breakage. Mass conservation also adds to the computational cost of the simulation partly because of these strategies, but mostly because the number of particles increases at a fast rate.

Mass conservation within the model is very important in process engineering applications, where mass control and mass ratios are key parameters. This is not so evident in geotechnical applications, such as pile driving, where the mechanical response of the system to an external load is the major interest. It is perhaps possible to correctly represent the macroscopic mechanical response while neglecting a mass fraction. This is the hypothesis explored here, where, at the post-processing stage, the mass of broken particles not included in the newly spawned particles is distributed in 
finer fractions. This facilitates the comparison of model results with experimental data on evolving porosity and specimen grain size distributions (GSDs).

The modelling choices explained above (multigenerational approach, non-conservative particle spawning procedure) have as a major underlying rationale the reduction of computational cost. A further step along this line is to use upscaled particle sizes, a technique previously applied in geotechnical engineering applications (Utili \& Nova, 2008; Gabrieli et al., 2009; Arroyo et al., 2011; Butlanska et al., 2013). Upscaling rules are here proposed for particle strength and for contact stiffness parameters, using both linear and Hertzian contact laws.

Increased computational efficiency would be counterproductive if the outcomes of the model were not realistic. The approach proposed in this paper is thus validated by simulating one-dimensional compression tests of materials with very different crushability. One example at the high end of crushability is given by petroleum coke (McDowell \& Bolton, 1998). At the low end of crushability, simulations of tests on Fontaineblau sand (Yang et al., 2010) and silica sand (McDowell, 2002) are presented. Model validation against the experimental results is performed using the observed macroscopic stress-strain response, by checking the at-rest stress pressure coefficient and, when available, by examining the evolution of grain sizes.

\section{MODEL DESCRIPTION}

The numerical models applied here were built using the PFC3D code (Itasca, 2008). This code implements the DEM in a similar form to that originally described by Cundall \& Strack (1979). As detailed below, interaction between particles was described either by a linear elastic or a simplified Hertz-Mindlin contact law with a friction limit. These contact laws are well known and described elsewhere (e.g. O'Sullivan, 2011); here the focus is placed on the particular ingredients that were newly specified for this work.

\section{Particle failure}

A variety of particle failure criteria have been used in the past by researchers applying the multigenerational approach. A grain failure criterion is a limit condition. Sometimes this condition has been cast directly as a limit on the maximum contact force acting on the particle (Astrom \& Herrmann, 1998; Marketos \& Bolton, 2009). More often the condition is posited as a limit on some characteristic strength that needs to be then related to the contact forces acting on the particle. For instance, Lobo-Guerrero \& Vallejo (2005) postulate a limit tensile strength that is related to forces acting on discs (they were working on two dimensions) by analogy to a Brazilian test, itself interpreted by a simplified uniform stress model. Ben-Nun \& Einav (2008) generalised this, using explicit multiplicative correction factors to account for the effects of coordination number and contact curvature.

Other approaches use as a starting point the average particle stress tensor (which can be derived from contact forces, see O'Sullivan (2011)). The limit condition is then expressed as a limit on this average stress state, usually taking the form of one of the classic failure conditions of solid mechanics. Thus, Tsoungui et al. (1999a) use a twodimensional (2D) equivalent of the Drucker-Prager criterion, and McDowell \& de Bono (2013) used a Von Mises criterion. Because of limiting average particle stress, contact related phenomena - such as stress concentrations - need to be separately introduced in the formulation.

The alternative proposed here deals with bulk and contact properties by means of a single coherent expression. Russell
\& Muir Wood (2009) combined a two-parameter material strength criterion with the analysis of the elastic stress distribution induced by point loads on a sphere to obtain a failure criterion. They obtained an analytical expression for maximum mobilised shear strength for a diametrically loaded sphere. The same expression was later proven valid for spheres within regular assemblies, with coordination numbers varying between 6 and 12 (Russell et al., 2009). As shown below, the mobilised shear strength expression provides a limit to the maximum contact force acting on a particle. This seemed a good basis on which to establish a failure criterion that was rigorous, versatile and computationally efficient.

The limit condition for grain failure derived by Russell \& Muir Wood (2009) can be expressed as

$$
\kappa_{\text {mob }} \leqslant \kappa
$$

where $\kappa_{\mathrm{mob}}$ and $\kappa$ are the mobilised and intrinsic strengths of the grains, respectively. The latter is derived from a biparametric strength criterion (Christensen, 2000), where the two parameters $\chi$ and $\kappa$ are related to the uniaxial compressive, $\sigma_{\mathrm{c}}$, and tensile, $\sigma_{\mathrm{t}}$, strengths of the material by

$$
\begin{aligned}
& \kappa=\frac{1+\chi}{\sqrt{3}}\left|\sigma_{\mathrm{c}}\right| \\
& \chi=\frac{\left|\sigma_{\mathrm{c}}\right|}{\sigma_{\mathrm{t}}}-1
\end{aligned}
$$

For most geological materials $\chi$ ranges from 10 to 170 (Goodman, 1989; Christensen, 2000). According to Christensen (2000) this parameter reflects microstructural properties of the material.

Analysing point load tests and assuming contacts with a small area, Russell \& Muir Wood (2009) show that $\kappa_{\text {mob }}$ is a maximum at a distance of $R \tan \theta_{0}$ below the centre of the contact (Fig. 1). They also give an approximate expression for the maximum mobilised strength that is valid for small contact angles:

$$
\begin{aligned}
\kappa_{\mathrm{mob}}= & \frac{\sqrt{3}(1+\chi)^{2}}{\chi} \\
& \times \frac{\left(\frac{3}{32}+\frac{\sqrt{2}}{24}+\left(\frac{\sqrt{2}}{12}-\frac{1}{4}\right) v+\left(\frac{1}{2}-\frac{\sqrt{2}}{3}\right) v^{2}\right)}{(2-\sqrt{2})(1+v)} \\
& \times \frac{F}{\pi R^{2} \sin ^{2} \theta_{0}}
\end{aligned}
$$

Russell et al. (2009) show that the same expression is, within the same degree of approximation, still valid for spheres under multiple contact loads. The force $F$ is now the

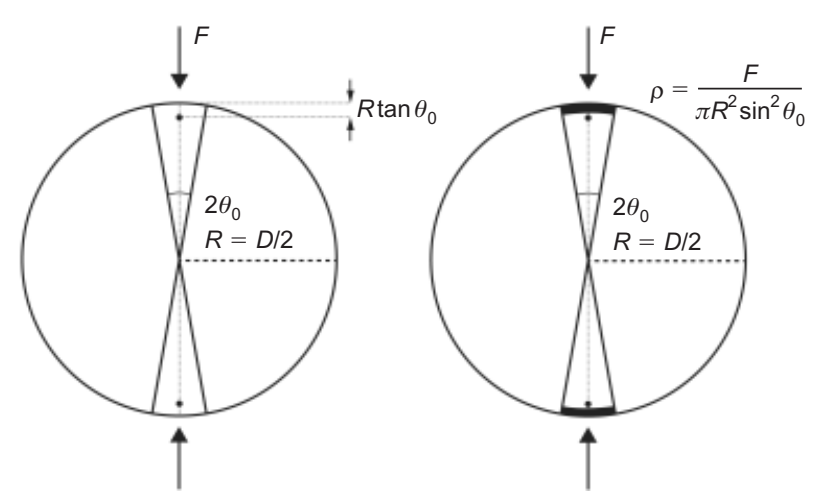

Fig. 1. Force $F$ acts normal to sphere surface on an area defined by the angle $\theta_{0}$. The equivalent stress acting on the area is $\rho$ 
maximum normal contact force acting on the sphere. The mobilised strength expression can be compactly written as

$$
\kappa_{\mathrm{mob}}=f(\chi, v) \frac{F}{\pi R^{2} \sin ^{2} \theta_{0}}
$$

where $v$ is the Poisson ratio and $\chi$ is the microstructure parameter defined above. $F$ is the load, $R$ is the sphere radius and $\theta_{0}$ is a solid angle 'seen' from the centre of the particle, which defines the small area of stress application. Substituting equation (4) in equation (1) results in a limiting criterion for the normal contact forces

$$
F \leqslant \frac{\kappa}{f(\chi, v)} \pi R^{2} \sin ^{2} \theta_{0}=\sigma_{\lim } A_{F}=F_{\lim }
$$

As indicated in equation (5) the limiting force is obtained as the product of a limit strength value, $\sigma_{\text {lim }}$, dependent on material parameters, and a contact area $A_{F}$. The clear separation of these two aspects of grain failure is one attractive aspect of this criterion, because properties governing contact area can take very different values in single grain tests and in granular assemblies. However, for practical application to discrete models of soils further development is necessary.

There is a large natural variability in shape, composition, microstructure and contact conditions in soils that is not reflected in the above model. This variability is observed, for instance, in single grain crushing experiments both as dispersion of force measurements for particles having the same nominal size and as a size dependency of the average strength values. To incorporate that variability into the simulation, the limit strength, defined as

$$
\sigma_{\lim }=\frac{\kappa}{f(\chi, v)}
$$

is assumed as normally distributed for a given sphere size. The coefficient of variation of the distribution is designated 'var.' and is considered a material parameter.

A size effect in particle strength, where smaller particles are stronger than larger ones, has been repeatedly observed in experiments. The validity of Weibullian statistics (Weibull, 1951), to describe granular crushing is still being debated. On the one hand, alternative explanations for size effect are also available (e.g. Alonso et al., 2012). On the other hand, the experimental evidence is ambiguous: some studies (Tsoungui et al., 1999b; McDowell \& Amon, 2000; Lobo-Guerrero \& Vallejo, 2006) have found that the same value of the Weibull modulus is able to fit both the variability at a given scale and the variability across scales, yet others (Jansen \& Stoyan, 2000; Lim et al., 2004; Brzesowsky et al., 2011) obtain the opposite result.

In this work size effect is incorporated as a dependency of the mean strength value on particle diameter through a correction factor, $f_{\text {size }}$. Although this correction factor is casted in a Weibull-like form, equation (7) is postulated only on a heuristic basis and, following McDowell \& de Bono (2013), is best simply described as a hardening rule.

$$
\begin{aligned}
\sigma_{\text {lim }} & =\sigma_{\text {lim }, 0} f_{\text {size }}(d) \\
f_{\text {size }}(d) & =\left(\frac{d}{d_{0}}\right)^{-3 / m}
\end{aligned}
$$

where $m$ is a material parameter and $\sigma_{\lim , 0}$ is the mean limit strength at $d_{0}$, which is the reference diameter (chosen as $2 \mathrm{~mm}$ ).

To evaluate the contact area $A_{F}$ in equation (5) several hypothesis can be made. Perhaps the simplest is to consider the contact solid angle $\theta_{0}$ as a material constant indepen- dently specified from $\sigma_{\text {lim. }}$. In this case the contact area at failure is given by

$$
A_{F}=\frac{\pi}{4} d^{2} \sin ^{2} \theta_{0}
$$

An alternative is to determine $A_{F}$ using Hertzian contact theory for smooth particles. It is then possible to express the contact area in terms of the elastic properties of the contacting materials ( $E$ and $v$ ) and the acting contact force. For smooth spheres the radius of the contact area is

$$
r_{\mathrm{H}}=\left(\frac{3 F r^{\prime}}{4 E^{\prime}}\right)^{1 / 3}
$$

where

$$
\begin{aligned}
& r^{\prime}=\left(\frac{1}{r_{1}}+\frac{1}{r_{2}}\right)^{-1} \\
& E^{\prime}=\left(\frac{1-v_{1}^{2}}{E_{1}}+\frac{1-v_{2}^{2}}{E_{2}}\right)^{-1}
\end{aligned}
$$

where $r_{1}$ and $r_{2}$ are the radius of the contacting spheres and $E_{1}, v_{1}$ their moduli.

Contact area and contact stiffness can be separately specified in the numerical model, with different degrees of refinement. In what follows, several combinations are explored: the constant failure solid angle model is combined both with a linear and a non-linear (Hertzian) stiffness model; Hertzian stiffness is also combined with the smooth Hertzian contact area model. More refined models for contact area, for instance using some measure of surface roughness, might also be easily implemented (e.g. Russell \& Muir Wood, 2009).

\section{Particle splitting and lost mass}

Once the limit condition is reached, a particle, modelled with a sphere in PFC 3D, will split into smaller inscribed tangent spheres. The daughter fragments assume the velocity and material parameters of the mother particle, except for the intrinsic strength $\left(\sigma_{\lim , 0}\right)$ that is randomly assigned respecting the normal distribution criteria.

It is clear that this way of modelling crushing does not conserve the mass within the numerical simulation. The underlying assumption here is that the mass lost is formed by finer particles that have a small influence on the macroscopic mechanical response. The heterogeneity of the magnitude of contact forces in discrete media force networks is well known (Radjai et al., 1996). The dominant role of distinct strong force chains in the mechanical macroscopic response has also been clearly established (Thornton \& Antony, 2000). More recently (Török et al., 2005), it was noted that larger particles do participate much more than smaller particles in force transmission through the granular mass. For the particular case of oedometric compression this is supported, for instance, by DEM analyses presented by Minh \& Cheng (2013).

On the other hand, when interpreting the test results, this mass should be accounted for. This is particularly important when tracking the evolution of the GSD during the test, a result that is frequently obtained in experiments. Some hypothesis about the size distribution of the lost mass is necessary. It has been repeatedly observed (e.g. Turcotte, 1986; McDowell et al., 1996; Altuhafi \& Coop, 2011) that grain crushing leads to the emergence of a fractal distribution of particle sizes, with fractal dimension $\alpha$ close to $2 \cdot 6$. Such distribution can be expressed (Einav, 2007) as 


$$
\frac{M_{(L<d)}}{M_{\mathrm{T}}}=\frac{d^{3-\alpha}-d_{\min }^{3-\alpha}}{d_{\max }^{3-\alpha}-d_{\min }^{3-\alpha}}
$$

where $M_{\mathrm{T}}$ is the total mass, $M_{(L<d)}$ is the mass of particles smaller than $d, d_{\max }$ is the maximum particle size and $d_{\min }$ is the minimum observed particle size. Accordingly, the deleted mass is assumed to distribute in particles fitting a fractal size distribution with exponent $2 \cdot 6, d_{\max }$ given by the smallest particle spawned during the crushing event and $d_{\min }$ given by the smallest diameter in the experimental GSD.

Figure 2 shows how this rule operates in a simple academic example. Consider as initial condition two spheres of $1 \mathrm{~mm}$ diameter and assume that one of them reaches the crushing limit condition, breaking into two smaller particles of $0.5 \mathrm{~mm}$ diameter each. In this situation $75 \%$ of that sphere or, equivalently, $37.5 \%$ of the total initial mass is lost. The lost mass is apportioned according to a fractal distribution characterised, in this example, by a maximum and minimum diameter of 0.5 and $0 \cdot 1 \mathrm{~mm}$, respectively. The

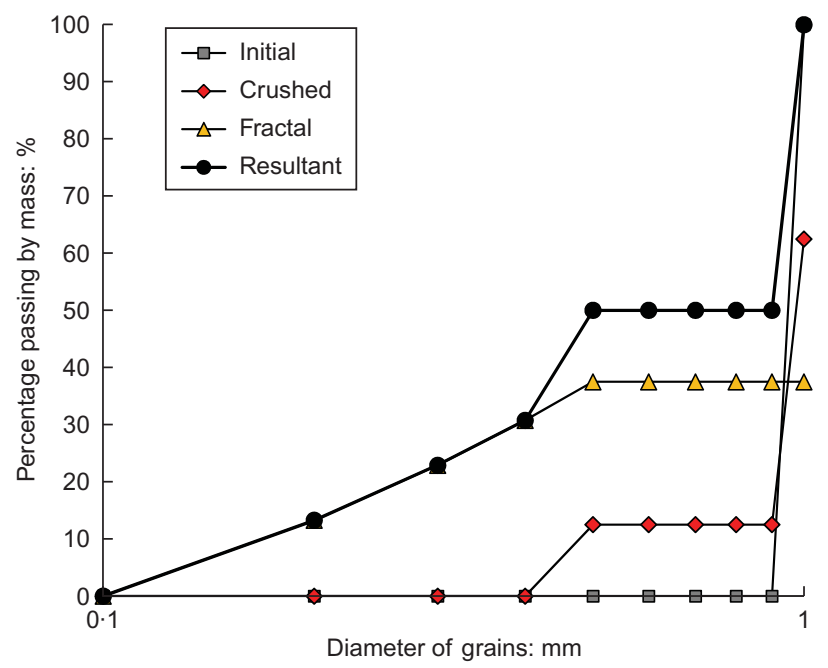

Fig. 2. Reconstruction of the GSD evolution

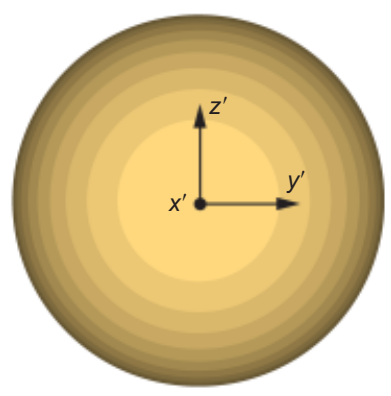

No-crush/intitial

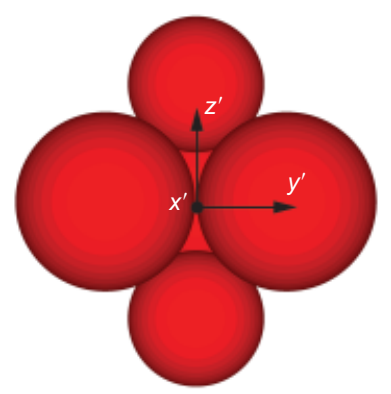

Five-ball $\mathrm{d} V=60 \%$

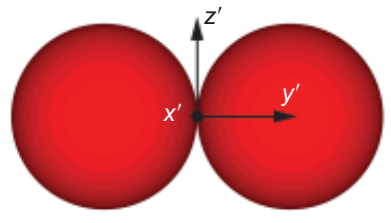

Two-ball $\mathrm{d} V=75 \%$

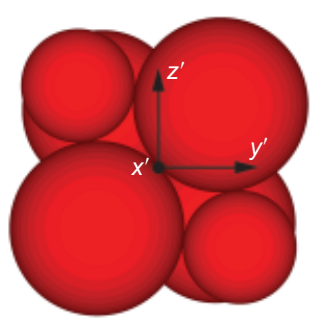

Eight-ball $d V=54 \%$

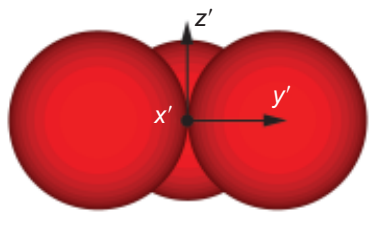

Three-ball $\mathrm{d} V=70 \%$

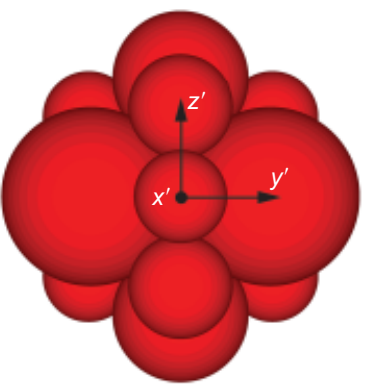

14 -ball $d V=47 \%$

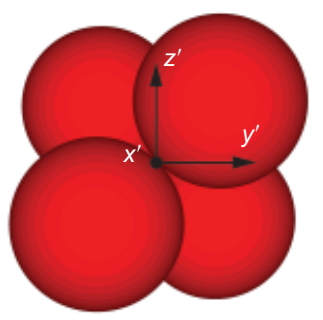

Four-ball $d V=64 \%$

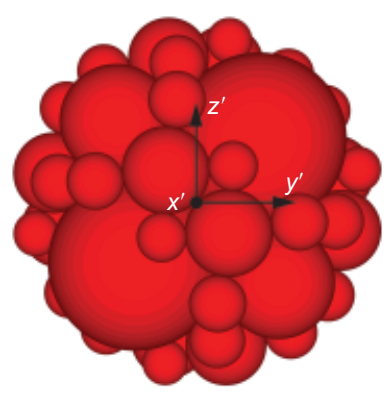

57-ball dV $=37 \%$

Fig. 3. Alternative configurations of sibling particles 


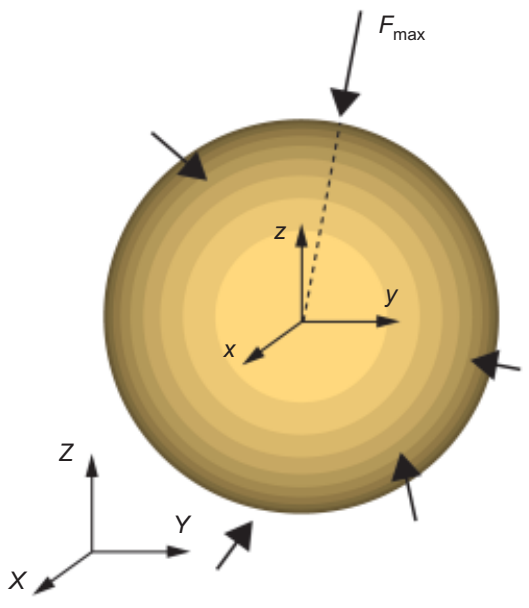

(a)

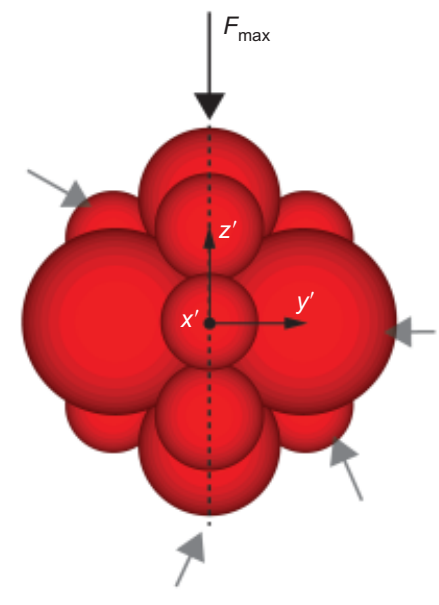

(b)

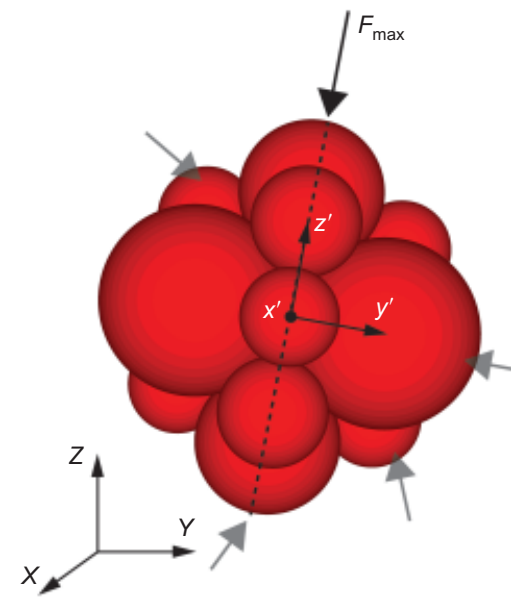

(c)

Fig. 4. Particle crushing configuration: (a) intact grain subject to five contact forces; (b) sibling disposition; (c) sibling reorientation

$\&$ de Bono (2013), using a $d_{\text {limit }} / d_{50}$ of $0 \cdot 25$, showed that compressibility was much reduced at high stresses, something frequently observed in the laboratory (Mesri \& Vardhanabhuti, 2009). However, this result might depend on other aspects of the model implemented.

A parametric study was performed to decide which splitting configuration to use in the simulations. The effect of the size of the larger particles in a splitting configuration was previously explored by McDowell \& de Bono (2013), who found it relatively inconsequential. The parametric study focused then on the number of particles to include in the splitting configuration and on the ratio $d_{\text {limit }} / d_{50}$.

Considering first the number of particles, the results showed that the macro-mechanical response (normal compression line (NCL)) of the discrete materials spawning 14ball and 57-ball gaskets on crushing was very similar (Fig. 5(a)). The comminution limit value had a larger effect. Raising its value made the inverted curvature of the compression line appear and resulted in a less evolved GSD (Fig. 5(b)). The value of the comminution limit controlled the rate of increase of computing time with number of particles in the splitting configuration (Fig. 5(c)).

On this basis the 14-ball crushed configuration represented in Fig. 3 was used in this work for all the simulations presented afterwards. The comminution limit for the different materials was chosen on a case-per-case basis, trying to minimise computational time while preserving the similitude with experimental results.

\section{Upscaling procedure}

Scaling up the particle size while maintaining constant other geometrical dimensions of the problem reduces the number of particles in the model (Fig. 6). An upscaling procedure is judged successful if the macroscopic quantities of interest such as compressibility, yield stress in NCLs and so on, remain unchanged. For this to be possible, the formulation of the contact laws needs to be modified to take into account the particle scaling factor, $N$. Also the grading evolution computed during compression should be correct when scaled back.

An upper limit to particle scaling is given by the relevant dimensions of the model. A sufficiently large number of particles should remain so that the granular media response is maintained in an average sense. In the simulations of onedimensional (1D) compression presented later, the most relevant dimension is the specimen diameter: in this work the integer scaling factors applied are such that specimen diameter is always one order of magnitude above the scaled average-particle diameter. Specimen height is less important here because no attempt is made to describe possible strain localisation inside the specimens. When localisation is of concern the strong horizontal boundary effects discussed by Marketos \& Bolton (2010) should be considered.

Stiffness. For the linear contact law Gabrieli et al. (2009) explain how the macroscopic stiffness is invariant to the grain scale if the normal $\left(k_{\mathrm{N}}\right)$ and tangential $\left(k_{\mathrm{S}}\right)$ contact stiffnesses are established according to the rule

$$
\begin{aligned}
& k_{\mathrm{N}}=2 K_{\text {eff }} \frac{D_{1} D_{2}}{D_{1}+D_{2}} \\
& k_{\mathrm{S}}=\alpha_{\mathrm{S}} k_{\mathrm{N}}
\end{aligned}
$$

where $D_{1}$ and $D_{2}$ are the diameters of the two spheres in contact and $K_{\text {eff }}$ and $\alpha_{\mathrm{S}}$, taken as 0.25 in all the linear contact model simulations presented in the following, are material constants. On the other hand, if the contact law is the simplified Hertz-Mindlin, the standard formulation (Itasca, 2008) is used since it already includes a similar scaling factor when calculating the normal and shear contact stiffness

$$
\begin{aligned}
& k_{\mathrm{N}}=\left(\frac{\left.2\langle G\rangle \sqrt{2 \frac{D_{1} D_{2}}{D_{1}+D_{2}}}\right) \sqrt{U}}{3(1-\langle v\rangle)}\right) \\
& k_{\mathrm{S}}=\left(\frac{2\left(\langle G\rangle^{2} 3(1-\langle v\rangle) \frac{D_{1} D_{2}}{D_{1}+D_{2}}\right)^{1 / 3}}{2-\langle v\rangle}\right)|F|^{1 / 3}
\end{aligned}
$$

where $U$ is the sphere overlap, $F$ is the magnitude of the normal contact force and the \langle\rangle brackets indicate the mean value of the quantity considered of the two balls in contact (shear modulus $G$ and Poisson ratio $v$ ).

Particle strength. Scaling of particle strength is made simple by the fact that a reference dimension is already present in the formulation of the size dependency factor in equation (7). The scale factor $N$ is then just factored in the definition of the reference dimension $d_{0}$. 

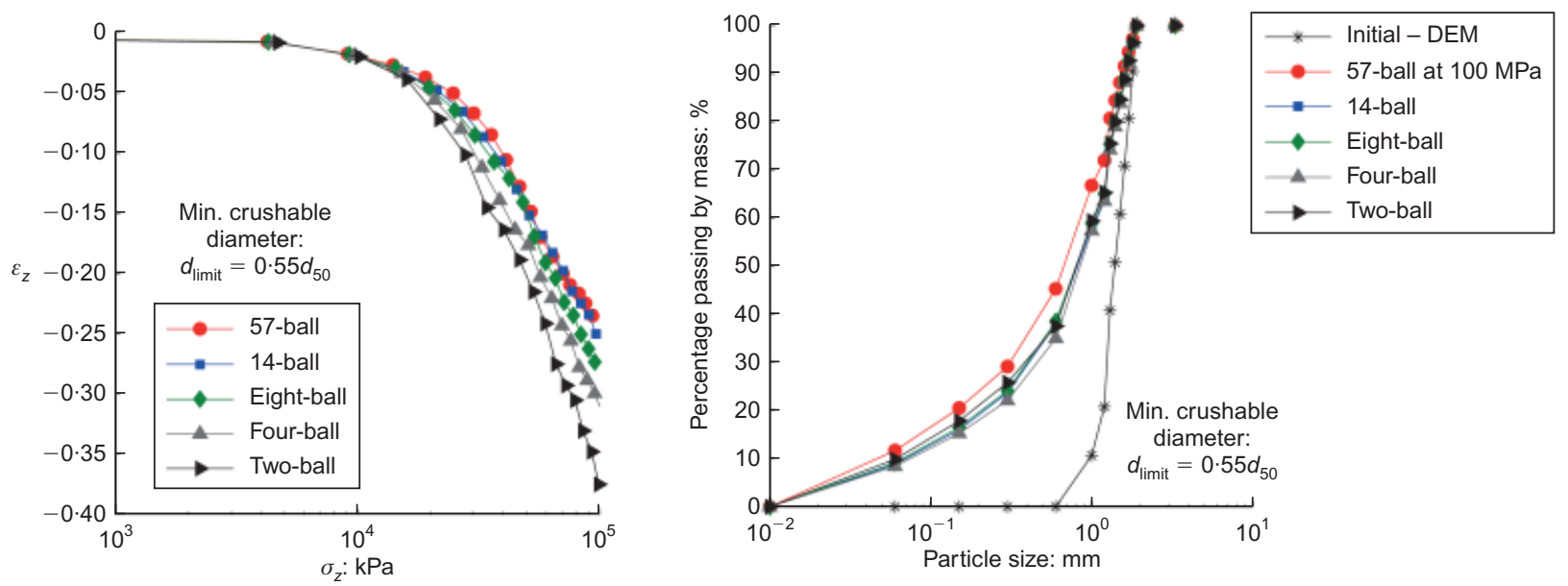

(a)
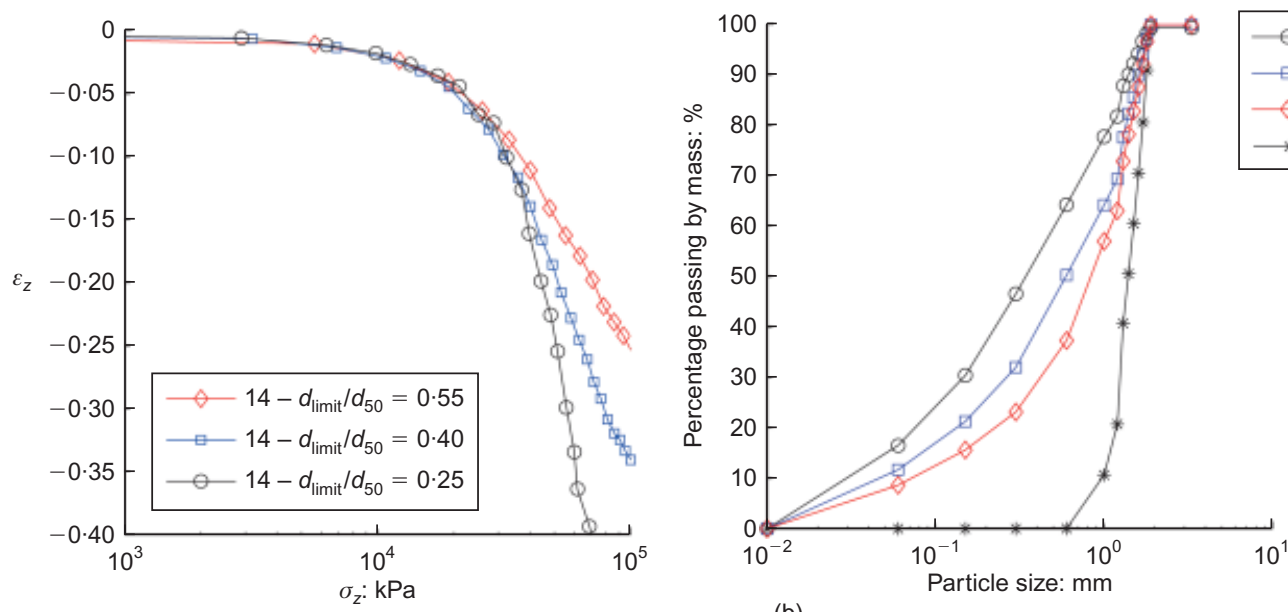

(b)
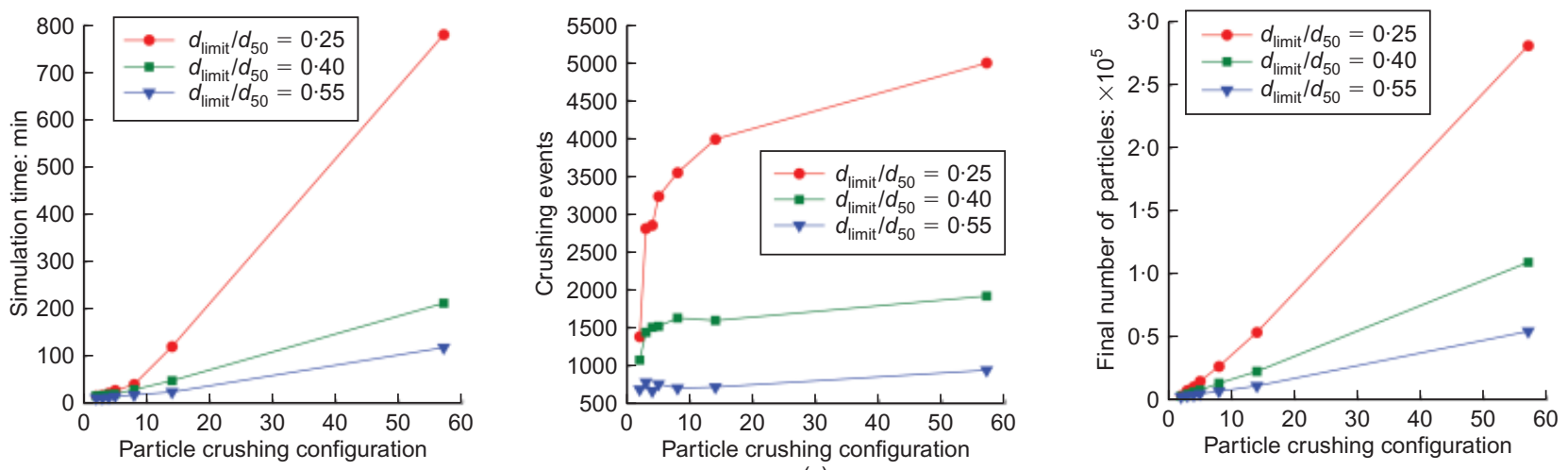

Fig. 5. Oedometric compression of a crushable sand. Parametric study on the effect on mechanical response: (a) of splitting configuration; (b) of $d_{\text {limit }} / d_{50}$ ratio. (c) Effect of the same variables on simulation time and final number of particles

$$
f_{\text {size }}=\left(\frac{d}{N d_{0}}\right)^{-3 / m}
$$

GSD. Uniform scaling of particle size shifts the GSD line towards the right proportionally to the scaling factor $N$. In order to compare GSD evolutions of the same test with different scaling factors all GSD are divided by the scale factor $N$ (downscaling procedure).

\section{Calibration}

In the model just described some material parameters are familiar from non-crushable DEM models. These are inter- granular friction $(\phi)$ and those relevant for the elastic contact laws ( $K_{\text {eff, }}, \alpha_{\mathrm{S}}$ for the linear one; $G$ and $v$ for the Hertzian one). Other parameters are new. These include the parameters describing crushability, namely var., $m, \sigma_{\lim , 0}$ and - only for the fixed contact breakage area model $-\theta_{0}$. As for the spawning procedure, here only the comminution limit $d_{\text {limit }}$ is left as a parameter, because the breakage configuration is fixed.

This adds to a total of six or seven parameters which, in principle, might all be obtained by matching several macroscopic test responses in a procedure similar to that used in continuum-based models or - within DEM - of bonded contact models for rocks (see e.g. Cheung et al., 2013). But other sources of information can also be used to calibrate or at least constrain the parameter values for any given material. 


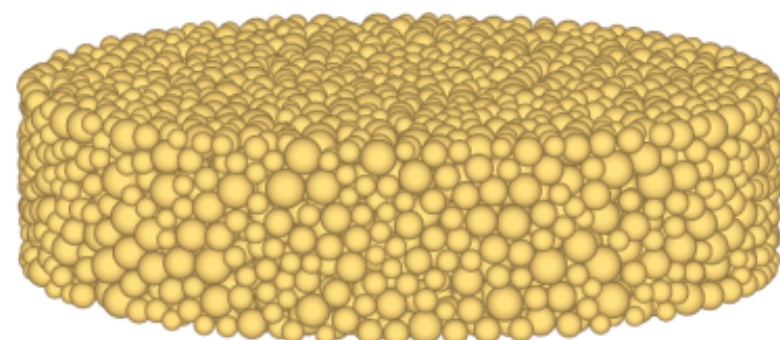

(a)

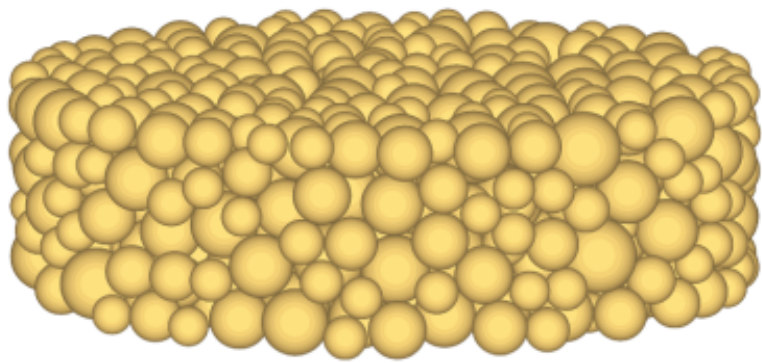

(b)

Fig. 6. (a) Scale 1 corresponding to 5388 particles and (b) scale 2 corresponding to 791 for the same oedometric compression test

The value $\sigma_{\text {lim }}$ is a property of the bulk material constitutive of the grains and, as defined in equation (6) is ultimately dependent on the material parameters entering the Russell and Muir Wood criterion $(v, \chi, \kappa)$ or, equivalently, $\left(v, \sigma_{\mathrm{c}}, \sigma_{\mathrm{t}}\right)$. For soils, however, this definition is difficult to apply, because $(a)$ the reference bulk material depends on the mineralogical composition of the grains, and $(b)$ precise data on tensile strength for geomaterials are relatively scarce. However, order of magnitude estimates can be obtained. For instance, a commercial grade fused silica (see http://www.mt-berlin.com), has values $\sigma_{\mathrm{c}}=1100 \mathrm{MPa}$ and $\sigma_{\mathrm{t}}=48 \mathrm{MPa}$, leading to $\chi=22$ and, assuming $v=0 \cdot 3$, to $\sigma_{\lim }=2300 \mathrm{MPa}$.

Single-grain platen crushing tests are well adapted to provide the parameters regarding variability of strength for a particular grain size (var.) and the variation of strength as a function of particle size $(\mathrm{m})$. If the contact angle at failure $\theta_{0}$ is assumed as a material constant, the crushing criterion in equation (5) limits the maximum force in a platen crushing test as follows

$$
F_{\lim } \leqslant \sigma_{\lim , 0}\left(\frac{d}{d_{0}}\right)^{-3 / m} \frac{\pi}{4} d^{2} \sin ^{2} \theta_{0}
$$

Alternatively, if Hertzian contact theory is used to calculate the evolution of contact area, for a single sphere loaded between platens the equivalent radius (equation (10)) is just $r^{\prime}=d / 2, v_{1}=v_{\text {particle }}, v_{2}=v_{\text {steel }}, E_{1}=E_{\text {particle }}, E_{2}=E_{\text {steel }}$ and the limit force reads

$$
F_{\lim } \leqslant\left[\sigma_{\lim , 0}\left(\frac{d}{d_{0}}\right)^{-3 / m} \pi\left(\frac{3 r^{\prime}}{4 E^{\prime}}\right)^{2 / 3}\right]^{3}
$$

Variability of strength for a particular grain size (var.) can be obtained representing crushing force distributions for given particle diameter, whereas the variability of strength with particle size $(m)$ can be derived from the mean crushing forces at various diameters. An example of the latter, for various materials, is given in Fig. 7 for the constant angle model and in Fig. 8 for the Hertzian area model. It is clear that the choice of contact area model does affect the value of the constant $m$ of the hardening law (equation (7)). The Hertzian area model requires larger $m$ values to fit the data slope, or, according to equation (7), a smaller correction factor.

Single-grain platen crushing tests also can provide estimates for other model parameters, albeit with a lower degree of accuracy. As reported in Table 1 and Table 2, several

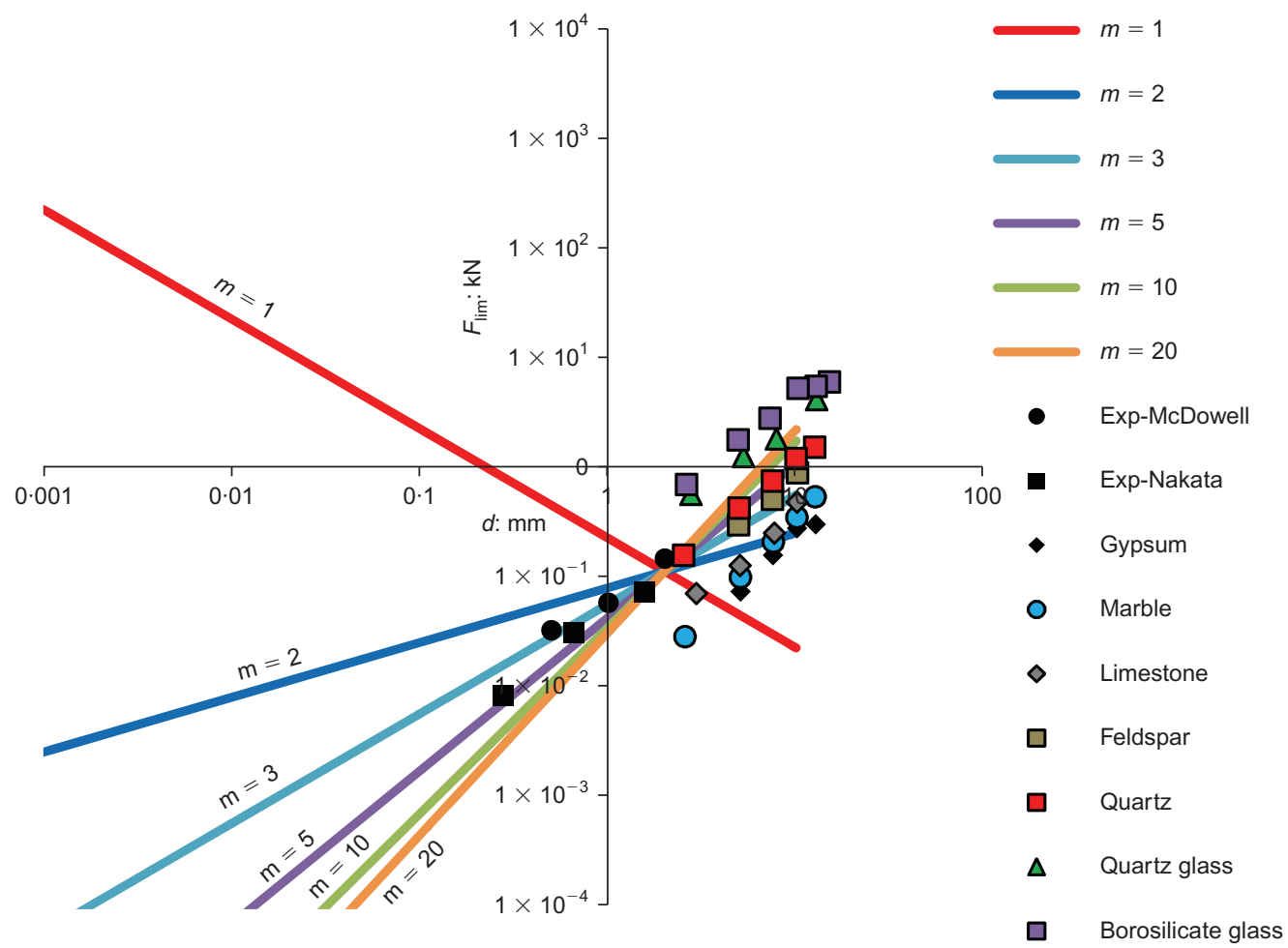

Fig. 7. Fixed contact area: particle limit contact force as a function of particle diameter for different $m$ values. In the same plot experimental results of single grain crush experiments; data from Yashima $e t$ al. (1987); Nakata et al. (2001); McDowell (2002) 

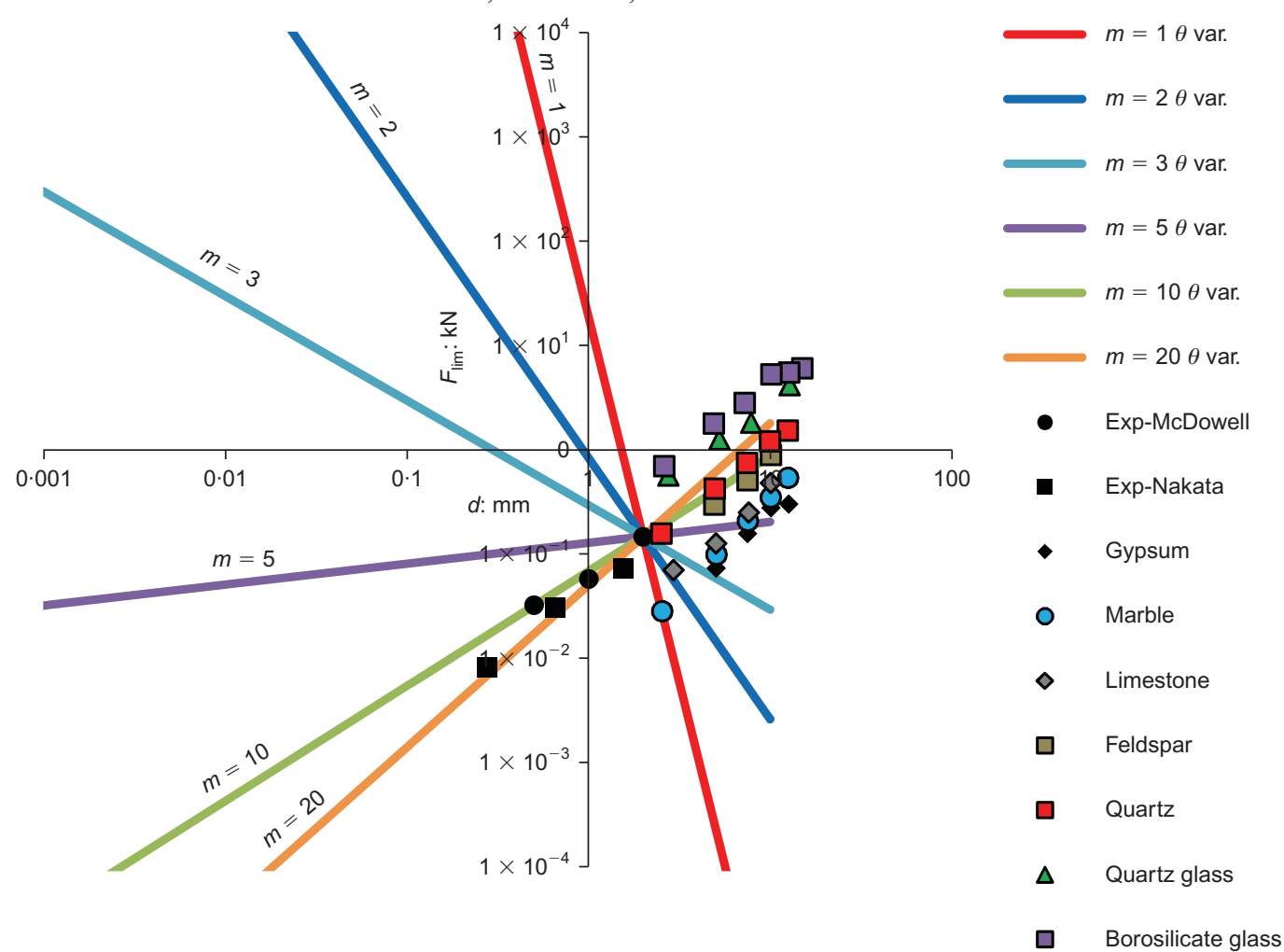

Fig. 8. Hertzian contact area: particle limit contact force as a function of particle diameter for different $m$ values. In the same plot experimental results of single grain crush experiments; data from Yashima et al. (1987); Nakata et al. (2001); McDowell (2002)

Table 1. Parameters of fixed contact angle model in Fig. 7

\begin{tabular}{l|c|c}
\hline$\theta_{0}: \mathrm{rad}$ & $\sigma_{\lim , 0}: \mathrm{MPa}$ & $d_{0}: \mathrm{mm}$ \\
\hline$\pi / 9$ & 300 & 2 \\
$\pi / 18$ & 1200 & 2 \\
$\pi / 24$ & 2060 & 2 \\
\hline
\end{tabular}

combinations of $\theta_{0}$ and $\sigma_{\lim , 0}-$ for the fixed contact area model - or of particle $G$ and $\sigma_{\text {lim, }, 0}$, can be chosen to plot the lines in Fig. 7 and in Fig. 8. These values can be used as guidance to choose relevant values for specimen simulations. It should be stressed that these estimates can only be approximate, since several aspects left out of the model particle shape, contact asperity, microflaw scaling, and so on - need not have the same influence on the mechanics of platen crushing and crushing within a granular mass. Further discussion on parameter calibration can be found in Ciantia et al. (2014).

\section{MODEL APPLICATION}

Simulations of 1D compression tests are presented for three different materials. The first is a weak (low stress) crushable material and the other two are relatively strong sands. The effect of three different modelling characteristics is investigated: contact stiffness description (linear or Hertzian); contact area description (fixed small angle or Hertzian); and scaling factor.

The simulation set is fully described in Table 3. The identification code of the numerical simulations (test-ID) employed in later figures is composed of two letters and a number. The first letter identifies the contact law (L stands for linear, $\mathrm{H}$ for Hertzian); the second letter indicates whether the contact angle is constant (C) or variable (V) and, finally, the number identifies the scaling factor applied to the material GSD. All the simulations employed a local non-viscous damping coefficient (Cundall, 1987) of 0.05.

Specimens were created to a relative density slightly above target value using the radius expansion method (Itasca, 2008). Velocities were then set to zero. Isotropic compression to $5 \mathrm{kPa}$ was used to obtain - by trial and error, using a temporary interparticle friction reduction - a closer fit (within $5 \%$ ) to the initial porosity target of each simulation. Once the target porosity was attained, friction was set to the final calibrated value and equilibrium was reached under an isotropic pressure of $5 \mathrm{kPa}$.

The geometry of the oedometer at $5 \mathrm{kPa}$ at the stable configurations for each sample is also reported in Table 3. As is the case for the reference experiments, the numerical tests took place under load control. The vertical stress during the simulations covered several orders of magnitude and a logarithmic control of the load increment was used

Table 2. Parameters of Hertzian contact area model in Fig. 8

\begin{tabular}{l|c|c|c|c|c|c|c}
\hline Material & $\sigma_{\text {lim }, 0}: \mathrm{MPa}$ & $d_{0}: \mathrm{mm}$ & $v_{\text {quartz }}$ & $G_{\text {particle }}: \mathrm{GPa}$ & $E_{\text {particle: GPa }}$ & $v_{\text {steel }}$ & $E_{\text {steel }}: \mathrm{GPa}$ \\
\hline Petroleum coke & 200 & 2 & $0 \cdot 3$ & $0 \cdot 33$ & $0 \cdot 866$ & $0 \cdot 3$ & 200 \\
Fontainebleau sand & 800 & 2 & $0 \cdot 3$ & 3 & $7 \cdot 8$ & $0 \cdot 3$ & 200 \\
Silica sand & 2200 & 2 & $0 \cdot 3$ & 18 & $46 \cdot 8$ & $0 \cdot 3$ & 200 \\
\hline
\end{tabular}


Table 3. Discrete-element method input parameters for simulation

\begin{tabular}{l|c|l|c|c|c|c|c|c|c|c|c|c|c|c|c|}
\hline Test-ID & $\begin{array}{c}\text { Scale, } \\
N\end{array}$ & $\begin{array}{l}\text { Contact } \\
\text { law }\end{array}$ & $\begin{array}{c}D \text { at } \\
5 \mathrm{kPa}: \\
\mathrm{cm}\end{array}$ & $\begin{array}{c}H \text { at } \\
5 \mathrm{kPa}: \\
\mathrm{cm}\end{array}$ & $\begin{array}{c}d_{50}: \\
\mathrm{mm}\end{array}$ & $\begin{array}{c}\text { Micro } \\
\text { porosity, } \\
n_{\text {int }}\end{array}$ & $\begin{array}{c}K_{\text {eff: }}: \\
\mathrm{MPa}\end{array}$ & $\phi: \mathrm{rad}$ & $\begin{array}{c}G: \\
\mathrm{GPa}\end{array}$ & $v$ & $\begin{array}{c}\sigma_{\text {lim, }, 0}: \\
\mathrm{MPa}\end{array}$ & $\theta_{0}: \mathrm{rad}$ & $m$ & Var. & $d_{\text {limit: }}: \mathrm{mm}$ \\
\hline
\end{tabular}

Petroleum coke

\begin{tabular}{l|l|l|l|l|l|l|l|l|l|l|l|l|l|l|l}
\hline L-C-1 & 1 & Linear & $20 \cdot 0$ & $5 \cdot 158$ & $7 \cdot 5$ & $0 \cdot 48$ & $33 \cdot 3$ & $0 \cdot 4$ & - & - & 300 & $\pi / 9$ & 2 & 1 & $0 \cdot 25 d_{50}$ \\
L-C-2 & 2 & Linear & $20 \cdot 0$ & $5 \cdot 977$ & $7 \cdot 5$ & $0 \cdot 48$ & $33 \cdot 3$ & $0 \cdot 4$ & - & - & 300 & $\pi / 9$ & 2 & 1 & $0 \cdot 25 d_{50}$ \\
H-C-1 & 1 & Hertzian & $20 \cdot 0$ & $5 \cdot 132$ & $7 \cdot 5$ & $0 \cdot 48$ & - & $0 \cdot 4$ & $0 \cdot 33$ & $0 \cdot 3$ & 300 & $\pi / 9$ & 2 & 1 & $0 \cdot 25 d_{50}$ \\
H-C-2 & 2 & Hertzian & $20 \cdot 0$ & $5 \cdot 183$ & $7 \cdot 5$ & $0 \cdot 48$ & - & $0 \cdot 4$ & $0 \cdot 33$ & $0 \cdot 3$ & 300 & $\pi / 9$ & 2 & 1 & $0 \cdot 25 d_{50}$ \\
H-V-1 & 1 & Hertzian & $20 \cdot 0$ & $5 \cdot 132$ & $7 \cdot 5$ & $0 \cdot 48$ & - & $0 \cdot 4$ & $0 \cdot 33$ & $0 \cdot 3$ & 200 & Equation (9) & 10 & 1 & $0 \cdot 25 d_{50}$ \\
H-V-2 & 2 & Hertzian & $20 \cdot 0$ & $5 \cdot 183$ & $7 \cdot 5$ & $0 \cdot 48$ & - & $0 \cdot 4$ & $0 \cdot 33$ & $0 \cdot 3$ & 200 & Equation $(9)$ & 10 & 1 & $0 \cdot 25 d_{50}$ \\
\hline
\end{tabular}

Fontainebleau sand

\begin{tabular}{|c|c|c|c|c|c|c|c|c|c|c|c|c|c|c|c|}
\hline L-C-5 & 5 & Linear & $2 \cdot 7$ & 0.984 & $0 \cdot 21$ & 0 & 300 & $0 \cdot 275$ & - & - & 820 & $\pi / 18$ & 3 & $0 \cdot 48$ & $0.55 d_{50}$ \\
\hline L-C-10 & 10 & Linear & $2 \cdot 7$ & 0.992 & $0 \cdot 21$ & 0 & 300 & $0 \cdot 275$ & - & - & 820 & $\pi / 18$ & 3 & $0 \cdot 48$ & $0.55 d_{50}$ \\
\hline H-C-5 & 5 & Hertzian & $2 \cdot 7$ & 0.983 & $0 \cdot 21$ & 0 & - & $0 \cdot 275$ & 3 & $0 \cdot 3$ & 820 & $\pi / 18$ & 3 & $0 \cdot 48$ & $0.55 d_{50}$ \\
\hline $\mathrm{H}-\mathrm{C}-10$ & 10 & Hertzian & $2 \cdot 7$ & 0.993 & $0 \cdot 21$ & 0 & - & $0 \cdot 275$ & 3 & $0 \cdot 3$ & 820 & $\pi / 18$ & 3 & $0 \cdot 48$ & $0.55 d_{50}$ \\
\hline $\mathrm{H}-\mathrm{V}-5$ & 5 & Hertzian & $2 \cdot 7$ & 0.993 & $0 \cdot 21$ & 0 & - & $0 \cdot 275$ & 3 & $0 \cdot 3$ & 1200 & Equation (9) & 10 & $0 \cdot 48$ & $0.55 d_{50}$ \\
\hline H-V-10 & 10 & Hertzian & $2 \cdot 7$ & 0.993 & $0 \cdot 21$ & 0 & - & $0 \cdot 275$ & 3 & $0 \cdot 3$ & 1200 & Equation (9) & 10 & 0.48 & $0.55 d_{50}$ \\
\hline
\end{tabular}

Silica sand

\begin{tabular}{l|l|l|l|l|l|l|l|l|l|l|l|l|l|l|l}
\hline H-C-1 & 1 & Hertzian & $4 \cdot 620$ & $1 \cdot 388$ & $1 \cdot 5$ & 0 & - & $0 \cdot 35$ & 18 & $0 \cdot 3$ & 5000 & $\pi / 24$ & 3 & $0 \cdot 48$ & $0 \cdot 55 d_{50}$ \\
H-C-2 & 2 & Hertzian & $4 \cdot 624$ & $1 \cdot 431$ & $1 \cdot 5$ & 0 & - & $0 \cdot 35$ & 18 & $0 \cdot 3$ & 5000 & $\pi / 24$ & 3 & $0 \cdot 48$ & $0 \cdot 55 d_{50}$ \\
H-V-1 & 1 & Hertzian & $4 \cdot 620$ & $1 \cdot 388$ & $1 \cdot 5$ & 0 & - & $0 \cdot 35$ & 18 & $0 \cdot 3$ & 5000 & Equation $(9)$ & 10 & $0 \cdot 48$ & $0 \cdot 55$ \\
H-V-2 & 2 & Hertzian & $4 \cdot 624$ & $1 \cdot 431$ & $1 \cdot 5$ & 0 & - & $0 \cdot 35$ & 18 & $0 \cdot 3$ & 5000 & Equation $(9)$ & 10 & $0 \cdot 48$ & $0 \cdot 55 d_{50}$ \\
\hline
\end{tabular}

$$
\sigma_{z}^{i+1}=\sigma_{z}^{i}+L_{\mathrm{C}}\left[\sigma_{\mathrm{ref}}+\log \left(\frac{\sigma_{z}^{i}}{\sigma_{\text {ref }}}\right)\right]
$$

where $L_{\mathrm{C}}$ is a load increase coefficient, $i$ indicates the step of the calculation and $\sigma_{\text {ref }}$ is a reference stress of $1 \mathrm{kPa}$. The coefficient $L_{\mathrm{C}}$ values applied in the simulations are reported in Table 4. They were chosen to attain the larger load steps that were compatible with quasi-static conditions.

Low-strength crushing material: petroleum coke

The reference experimental test used here is a $1 \mathrm{D}$ normal compression curve for petroleum coke reported alongside its

Table 4. Discrete-element method model results

\begin{tabular}{|c|c|c|c|c|c|c|c|c|c|}
\hline Test-ID & Scale, $N$ & Contact Law & $L_{\mathrm{C}}$ & $d_{\text {limit }}: \mathrm{mm}$ & $\begin{array}{l}\text { Initial number } \\
\text { of particles }\end{array}$ & $\begin{array}{l}\text { Final number } \\
\text { of particles }\end{array}$ & Crush events & $\begin{array}{l}\text { Excluded } \\
\text { particles }\end{array}$ & $\begin{array}{l}\text { Model run: } \\
\text { min }\end{array}$ \\
\hline \multicolumn{10}{|c|}{ Petroleum coke } \\
\hline L-C-1 & 1 & Linear & 0.01 & $1 \cdot 875$ & 5388 & 90525 & 6549 & $1.4 \times 10^{6}$ & 251 \\
\hline L-C-2 & 2 & Linear & $0 \cdot 01$ & 1.875 & 791 & 19004 & 1401 & $3 \cdot 1 \times 10^{5}$ & 68 \\
\hline $\mathrm{H}-\mathrm{C}-1$ & 1 & Hertzian & 0.01 & $1 \cdot 875$ & 5388 & 99209 & 7217 & $1.6 \times 10^{6}$ & 316 \\
\hline H-C-2 & 2 & Hertzian & $0 \cdot 01$ & 1.875 & 680 & 18984 & 1408 & $3 \cdot 1 \times 10^{5}$ & 48 \\
\hline $\mathrm{H}-\mathrm{V}-1$ * & 1 & Hertzian & 0.01 & 1.875 & 5388 & 171918 & 12810 & $2.8 \times 10^{6}$ & 1020 \\
\hline $\mathrm{H}-\mathrm{V}-2^{*}$ & 2 & Hertzian & 0.01 & 1.875 & 680 & 22988 & 1716 & $3.8 \times 10^{5}$ & 268 \\
\hline $\mathrm{H}-\mathrm{V}-1^{\dagger}$ & 1 & Hertzian & $0 \cdot 01$ & $1 \cdot 875$ & 5388 & 231809 & 17417 & $3.8 \times 10^{6}$ & 3682 \\
\hline $\mathrm{H}-\mathrm{V}-2^{\dagger}$ & 2 & Hertzian & $0 \cdot 01$ & $1 \cdot 875$ & 680 & 34415 & 2595 & $5 \cdot 7 \times 10^{5}$ & 1087 \\
\hline
\end{tabular}

Fontainebleau sand

\begin{tabular}{l|r|l|r|r|r|r|r|r|r}
\hline L-C-5 & 5 & Linear & $0 \cdot 1$ & $0 \cdot 1155$ & 8932 & 20060 & 856 & $1 \cdot 9 \times 10^{5}$ & 300 \\
L-C-10 & 10 & Linear & $0 \cdot 1$ & $0 \cdot 1155$ & 1122 & 2734 & 124 & $2 \cdot 7 \times 10^{4}$ & 55 \\
H-C-5 & 5 & Hertzian & $0 \cdot 1$ & $0 \cdot 1155$ & 8932 & 31448 & 1732 & $3 \cdot 8 \times 10^{5}$ & 340 \\
H-C-10 & 10 & Hertzian & $0 \cdot 1$ & $0 \cdot 1155$ & 1122 & 4502 & 260 & $5 \cdot 7 \times 10^{4}$ & 50 \\
H-V-5 & 5 & Hertzian & $0 \cdot 1$ & $0 \cdot 1155$ & 8932 & 24116 & 1168 & $2 \cdot 6 \times 10^{5}$ & 475 \\
H-V-10 & 10 & Hertzian & $0 \cdot 1$ & $0 \cdot 1155$ & 1122 & 3137 & 155 & $3 \cdot 4 \times 10^{4}$ & 55 \\
\hline
\end{tabular}

Silica sand

\begin{tabular}{l|l|l|l|l|r|r|r|r|r}
\hline H-C-1 & 1 & Hertzian & $0 \cdot 1$ & $0 \cdot 825$ & 13849 & 138935 & 9622 & $2 \cdot 1 \times 10^{6}$ & 1890 \\
H-C-2 & 2 & Hertzian & $0 \cdot 1$ & $0 \cdot 825$ & 1736 & 18779 & 1311 & $2 \cdot 9 \times 10^{5}$ & 263 \\
H-V-1 & 1 & Hertzian & $0 \cdot 1$ & $0 \cdot 825$ & 13849 & 102522 & 6821 & $1 \cdot 5 \times 10^{6}$ & 1028 \\
H-V-2 & 2 & Hertzian & $0 \cdot 1$ & $0 \cdot 825$ & 1736 & 13995 & 943 & $2 \cdot 1 \times 10^{5}$ & 131 \\
\hline
\end{tabular}

* Values for simulations $\mathrm{H}-\mathrm{V}-1$ and $\mathrm{H}-\mathrm{V}-2$ until $5 \mathrm{MPa}$ vertical stress (similar to the others for this material).

$\dagger$ Values for simulations $\mathrm{H}-\mathrm{V}-1$ and $\mathrm{H}-\mathrm{V}-2$ until $10 \mathrm{MPa}$ vertical stress (as shown in Fig. 10). 
evolving particle size distribution by McDowell \& Bolton (1998) (Fig. 9).

The grains of this material are very porous. To account for this micro-porosity, the DEM particles themselves are assumed to have constant porosity, $n_{\text {int }}$, taken as $48 \%$ in correspondence with typical values for activated carbons (Díaz-Terán et al., 2001). Particle microporosity is assumed independent of particle size and not affected by breakage. This hypothesis only holds if the micropores are much smaller than the particle itself and, since this study is dealing with large particles (Fig. 9), the hypothesis is assumed to be valid. The latter assumption allows the real solid volume of a grain to be calculated

$$
V_{\mathrm{s}}^{*}=V_{\mathrm{s}}\left(1-n_{\mathrm{int}}\right)
$$

and hence the porosity of an ensemble of porous grains

$$
n^{*}=1-(1-n)\left(1-n_{\text {int }}\right)
$$

There were no other mechanical tests available for this

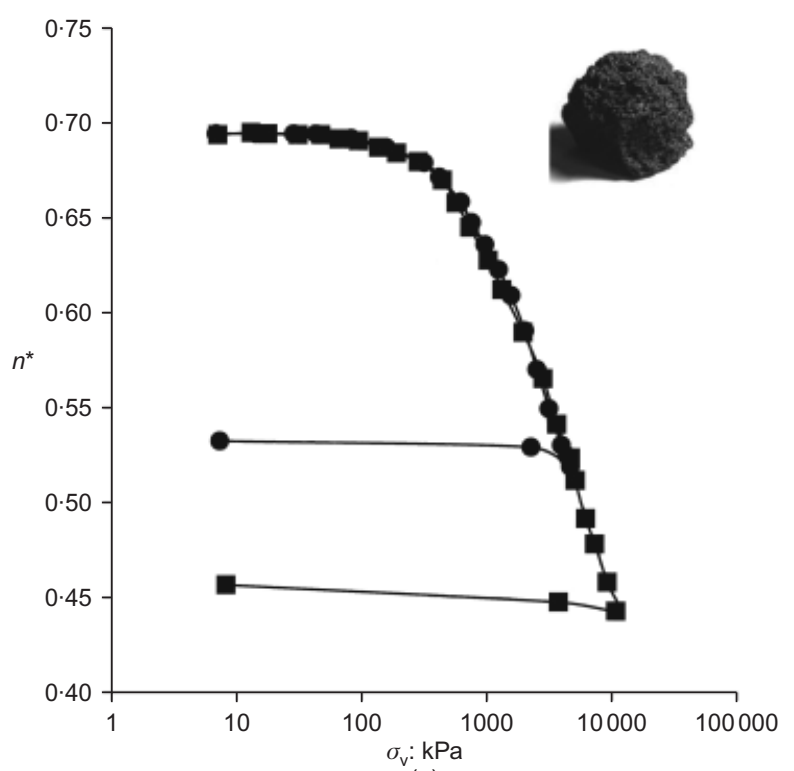

(a)

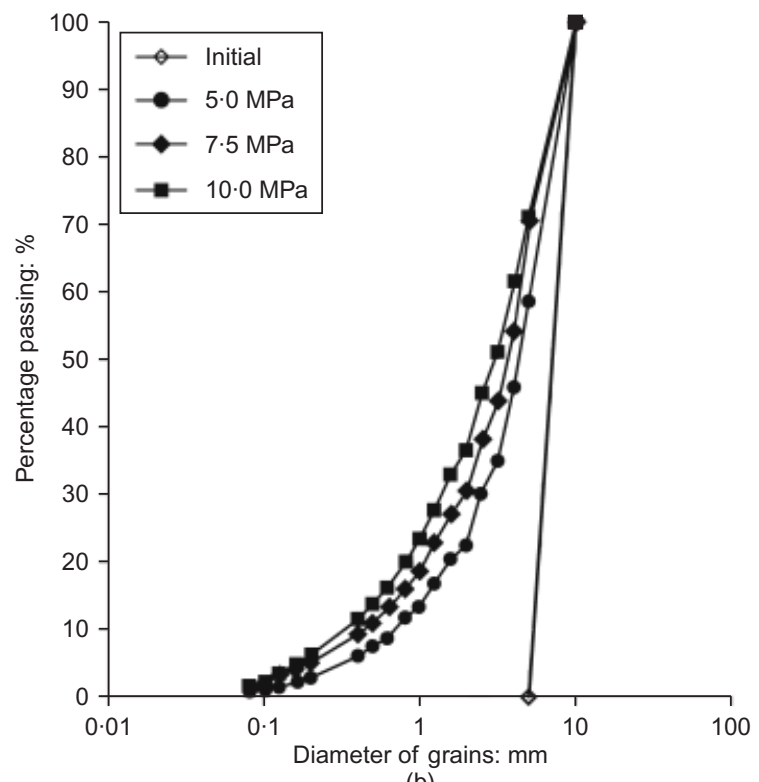

(b)

Fig. 9. (a) One-dimensional normal compression curve and (b) evolving particle size distribution for petroleum coke. (Data from McDowell \& Bolton (1998)) material. Some material parameters $\left(K_{\text {eff }} \phi, G\right)$ were calibrated by fitting the pre-yield stretch of the NCL. The yield stress itself was used to select the value of $\sigma_{\lim 0}$. There were no single particle crush data for coke. Granular microporous soils have shown (McDowell \& Amon, 2000) larger withinsize variability and smaller across-sizes variability than nonmicroporous soils. Hence var. was assigned a value of 1 . Relatively low values of $m$ were initially selected in the range suggested by Fig. 2 and Fig. 3 and then adjusted to fit the post-yield behaviour. The comminution limit $d_{\text {limit }}$ was chosen relatively low $\left(0 \cdot 25 d_{50}\right)$ because particle size for this material was initially large.

Figure 10 shows the results of DEM simulations of oedometric compression for this material, both at scale 1 and 2. The behaviour in compression of this material is dominated by crushing. Simulations without crushing were also performed for the different contact models. As shown in the figure, without crushing no model is able to approximate the experimental behaviour. At high pressures the nonlinear Hertzian stiffness results in less deformation than the linear contact law, but that is a result of excessive particle overlap.

As expected, the numerical result is far more realistic after crushing is activated (Figs 10(a) and 10(b)). The effect of the contact stiffness hypothesis (linear or Hertzian) is not significant. The effect of the assumption about contact area is secondary to that of activating crushing, but still significant. Simulations with a variable (Hertzian) contact area do result in a better reproduction of the experimental compression curve (Figs 10(e) and 10(f)). During the first stages of compression, particularly in Figs 10(b) and 10(d), a kink does appear in the simulated GSD. This is an artefact of the splitting configuration chosen: in this very uniform material (initial ratio of largest to smallest particle is 2) the largest possible daughter particle of the initial material has a diameter smaller than the initial minimum size. In other words, there is no overlap between initial particle and fragment sizes. An interesting result is that, independently of the different constitutive hypothesis applied, upscaling by a factor of 2 does seem to have a very minor effect on the macroscopic outcomes of the simulations.

The forces acting during the simulation against the radial confining wall are easily integrated to evaluate horizontal stress and, therefore, the lateral pressure coefficient, $k_{0}$, defined as the ratio between radial and vertical stress. Fig. 11 shows again how the dominant effect here is that of crushing, and that both linear and Hertzian - be that with constant or variable contact angle - contact laws give very similar results in terms of $k_{0}$ and stress paths in the $q-p$ plane. Note that the initial isotropic state $\left(k_{0}=1\right)$ is an artefact due to the sample formation procedure.

The classic experimental trends summarised by Mesri \& Vardhanabhuti (2009) are well captured by the DEM simulations. Dense, crushable soils start with a low value of $k_{0}$; during crushing compression a linear increase occurs until they reach an asymptotic value related, by Jaky's formula, to their constant volume friction angle. The asymptotic value of $k_{0}$ depends somewhat on the chosen contact model; the equivalent friction angle of the Hertzian contact models is higher than that of the linear model.

\section{High-strength crushing material no. 1: Fontainebleau sand}

In the previous section it was observed that, for highly crushable materials, the use of a linear or Hertzian contact model did not produce major differences in terms of mechanical response and GSD evolution. However, when considering strong materials, the elastic components of 


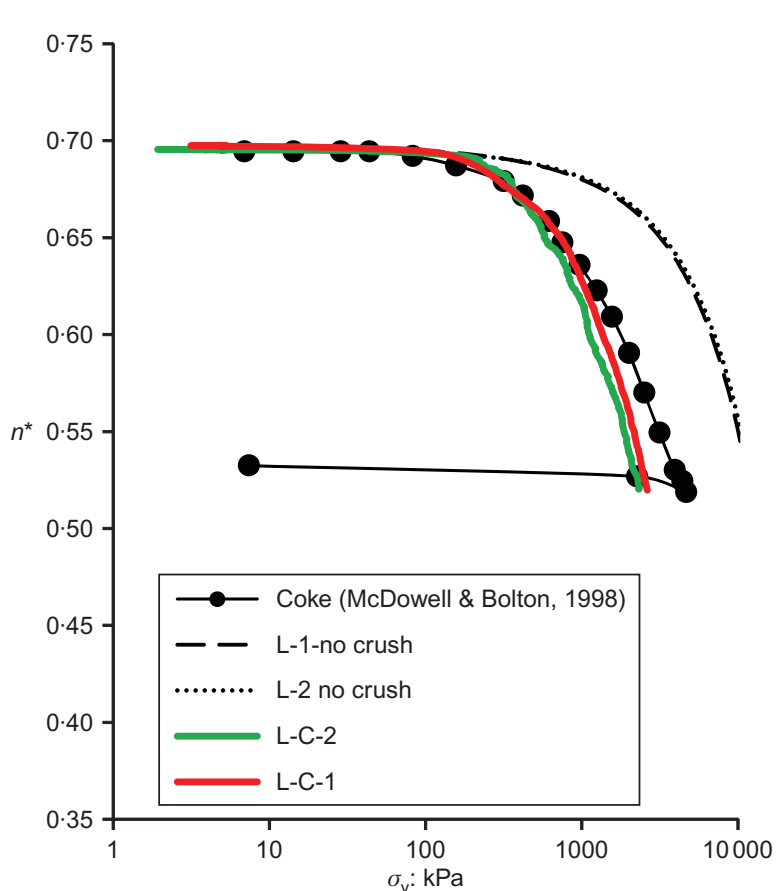

(a)

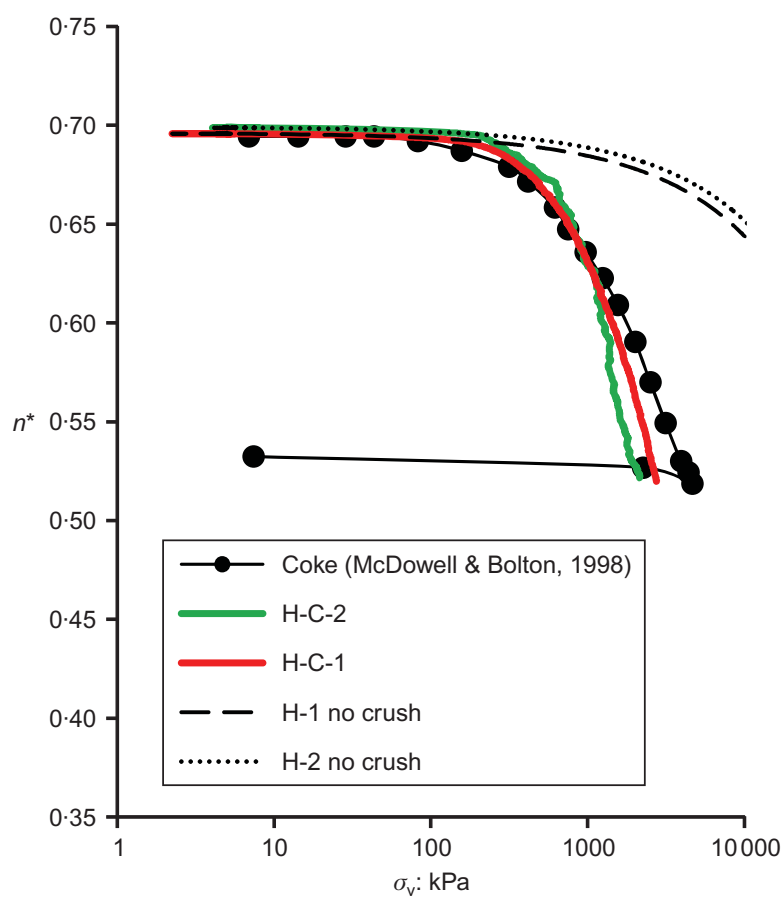

(c)

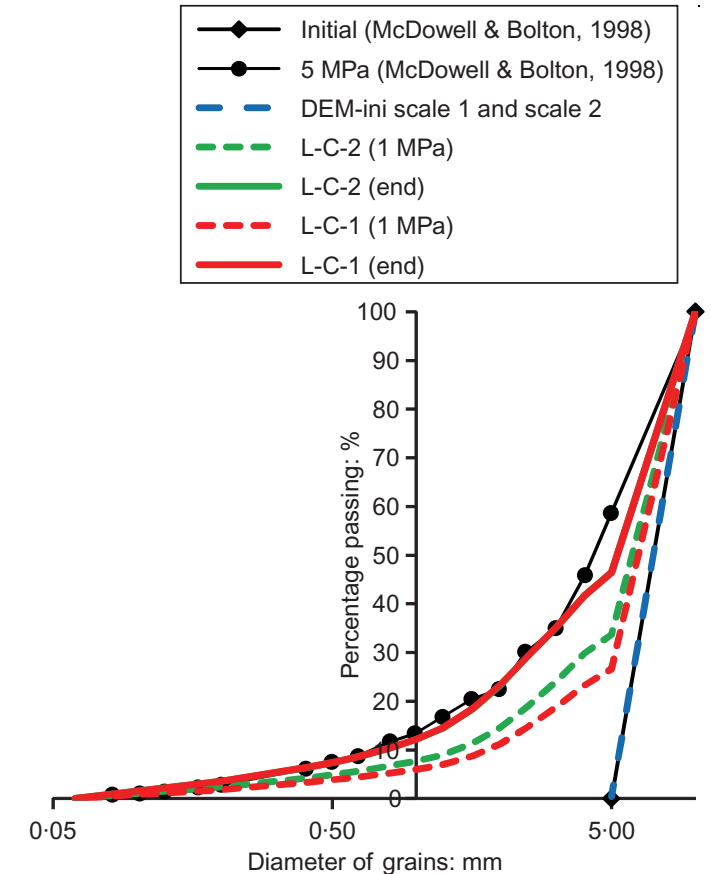

(b)

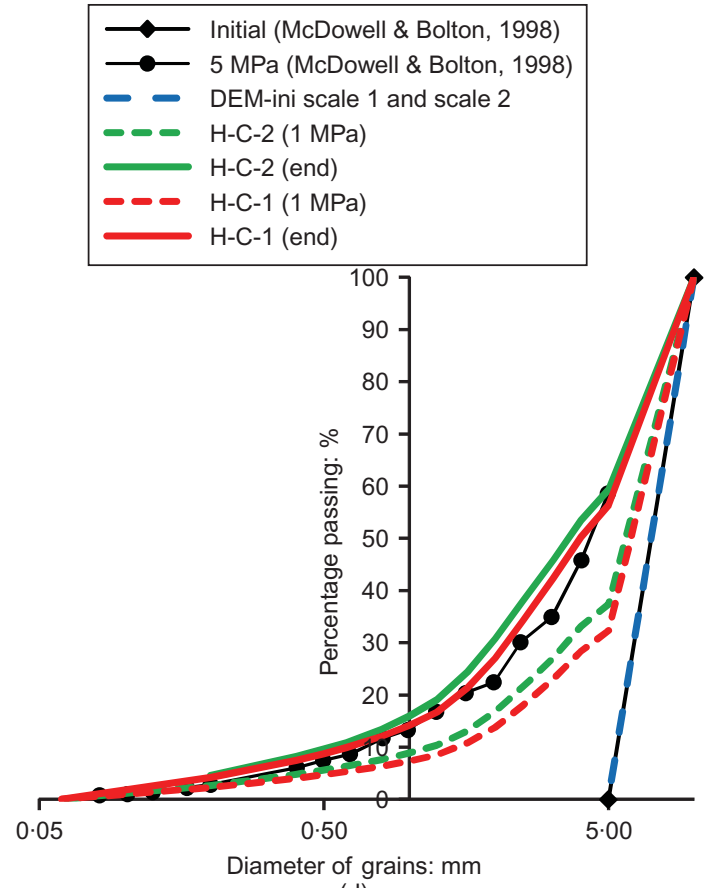

(d)

Fig. 10. Comparison of scale 1 and scale 2 DEM simulations and experimental data of one-dimensional compression tests for petroleum coke: (a), (c) and (e) in compression law; (b), (d) and (f) GSD evolution; (g) to (i) show the initial and final configurations of the models. The darker particles in parts (g) to (i) represent particles spawned after breakage (red, blue and black particles represent first, second and third generation of particles, respectively) (continued)

deformation are more important and contact stiffness should play a larger role.

A high-stress oedometer on Fontaineblau sand reported by Yang et al. (2010) is used as an example. Low-confiningpressure triaxial compression results by Seif El Dine (2007) and Seif El Dine et al. (2010), as shown in Fig. 12(a) and Fig. 12(b), were used here to calibrate basic DEM contact parameters $\left(K_{\text {eff }}, \phi, G\right)$. The triaxial simulations were performed without crushing, because crushing is small at low confining pressure. For the high-pressure oedometer, as illustrated in Fig. 12(c), the models without crushing are inappropriate. At high pressures the two simulations bracket the experimental result, with the linear model being too compliant and the Hertzian model too rigid. No specific particle crushing tests were available for this case and the parameters controlling grain strength variability ( $m$ and var.) were assumed equal to those of other siliceous sands represented in Fig. 2 and Fig. 3. Tables 1 and 2 were used to guess initial values for $\sigma_{\lim 0}$ and $\theta_{0}$, later slightly adjusted to capture yield stress. The comminution limit $d_{\text {limit }}$ is higher here $\left(0.55 d_{50}\right)$ because particle size for this material was initially small. 


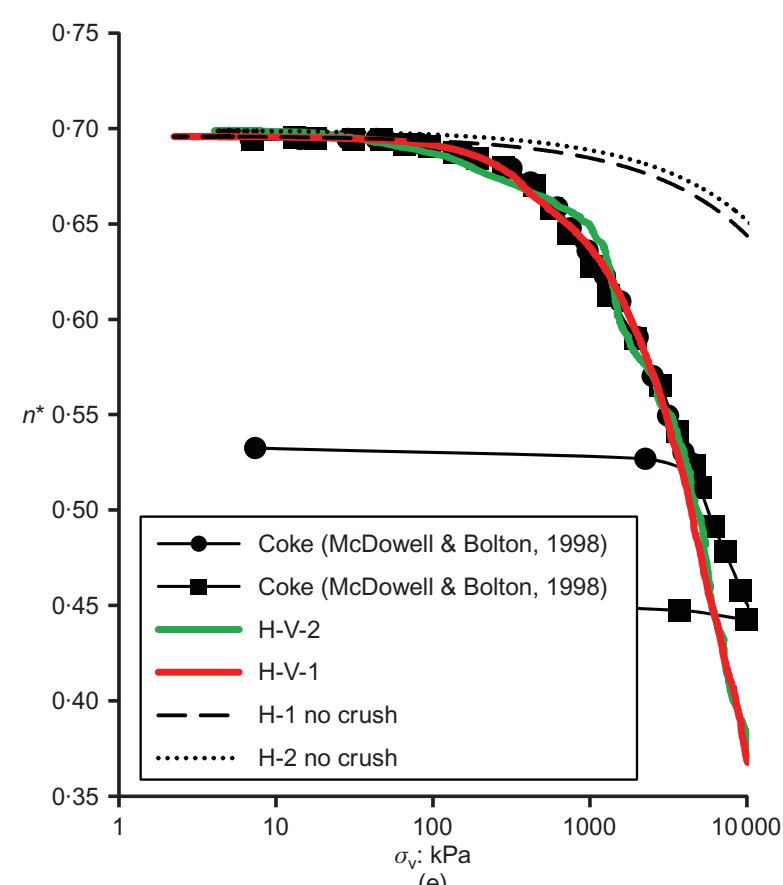

(e)

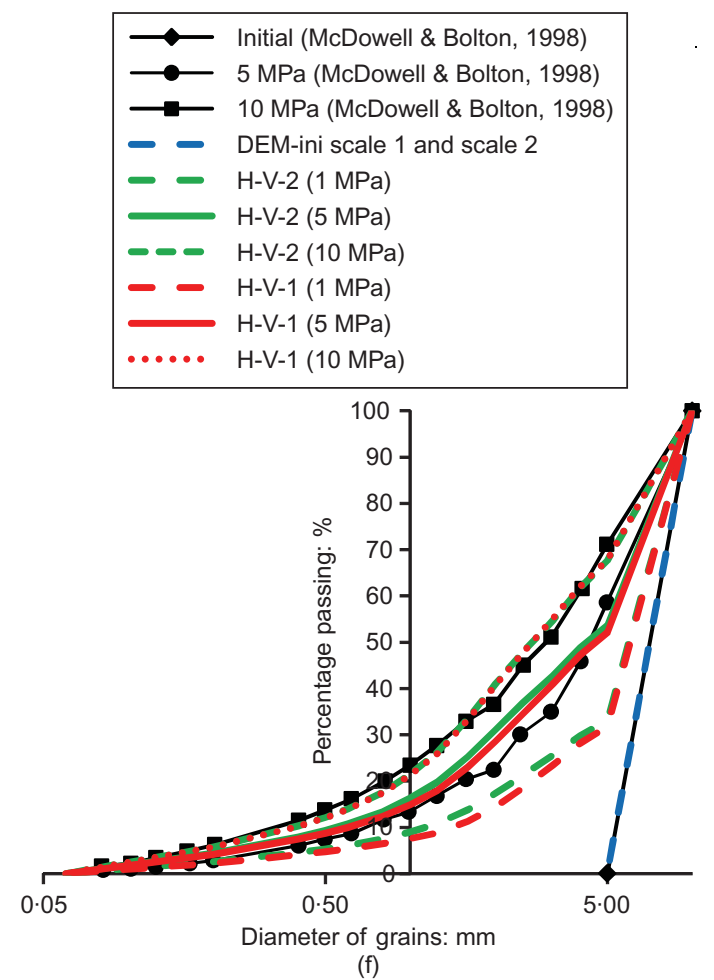

(f)
$\mathrm{L}-\mathrm{C}-1$

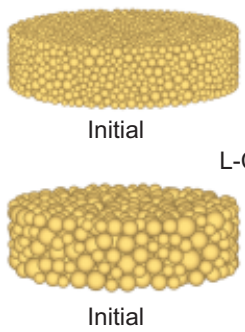

(g)

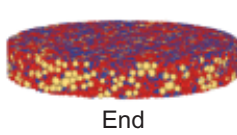

$-\mathrm{C}-2$
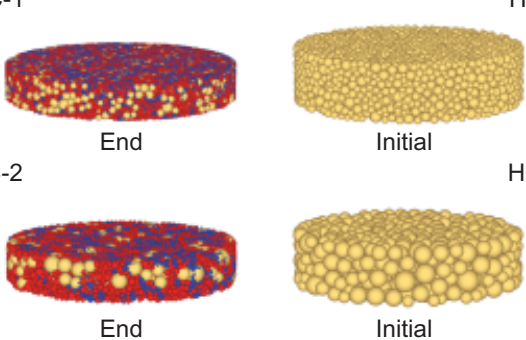

Initial

$\mathrm{HC}-2$

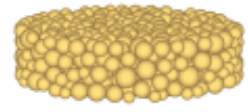

Initial

(h)
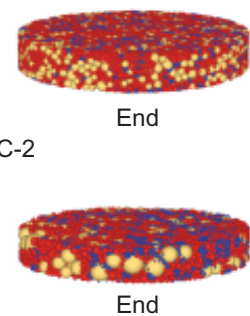

\section{nd}

End

(1)

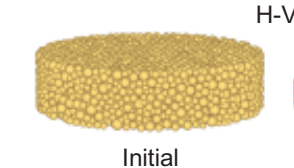

Initial

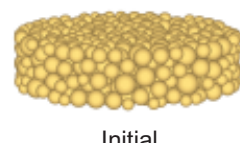

Initial
$\mathrm{H}-\mathrm{V}-1$

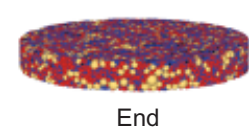

HV-2

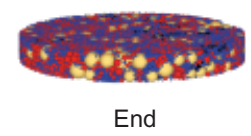

(i)

Fig. 10. (Continued)

Activating crushing significantly increases the curvature of the NCL beyond the stress level marked by $\sigma_{\lim , 0}$. While this causes the NCL to move further away from the experimental data for the linear contact model simulation, in the Hertzian contact model this crushing induced deformation brings the simulation closer to the experimental results (Figs 13(a) and 13(b)). Introducing the Hertzian contact area model has the opposite result (i.e. reducing the curvature) at high stresses. Unfortunately, the experimental data do not reach the stress level at which the constant and Hertzian contact models diverge, nor do they include evolution of the GSD for this test. In Figs 13(c) and 13(d) it can be seen, however, that the linear contact model has resulted here in less fragmentation than the Hertzian contact model simulations. The Hertzian model remains stiffer at high pressures, and therefore more contacts attain the crushing limit condition. The macroscopic results appear quite insensitive to a doubling of the scale factor (from 5 to 10) for all the different contact models tested.

The stress paths and simulated $k_{0}$ evolution are presented in Fig. 14. With or without crushing, the linear contact model shows a behaviour that does not converge to a horizontal $k_{0}$ asymptote, contrary to general evidence (e.g. Mesri \& Vardhanabhuti, 2009). In contrast, the Hertzian model with crushing does lead to a behaviour converging to an asymptotic $k_{0}$ value. The Jaky-inferred asymptotic friction angle inferred from the simulations $\left(29^{\circ}\right.$ and $\left.33^{\circ}\right)$ is close to the value suggested by the low-density triaxial test in Fig. 12(a).

High particle strength poses a problem to the linear model implemented here, because the tests attain large stresses. As noted by Mašín (2012), when using uncrushable particles, the 1D compression line will eventually curve above 10 $20 \mathrm{MPa}$ (Fig. 12(c)) owing to particle overlap. This effect can be corrected by selecting a very high contact stiffness, but this, in turn, will not allow the initial part of the curve to be captured correctly.

\section{High-stress crushing material no. 2: silica sand}

McDowell (2002) presents oedometric results for another strong silica sand that go further in terms of applied stress and also include GSD. This experiment was later simulated using aggregates by McDowell \& Harireche (2002) and single particles by McDowell \& de Bono (2013). McDowell (2002) also presents grain crush data for this sand. The grain crush data were used to establish var. and $m$. Contact parameters (Table 3 ) were again calibrated using the initial elastic part of the curve $\left(\phi, G, K_{\text {eff }}\right)$. Tables 1 and 2 were used to guess initial values for $\sigma_{\lim 0}$ and $\theta_{0}$; the location of the yield 


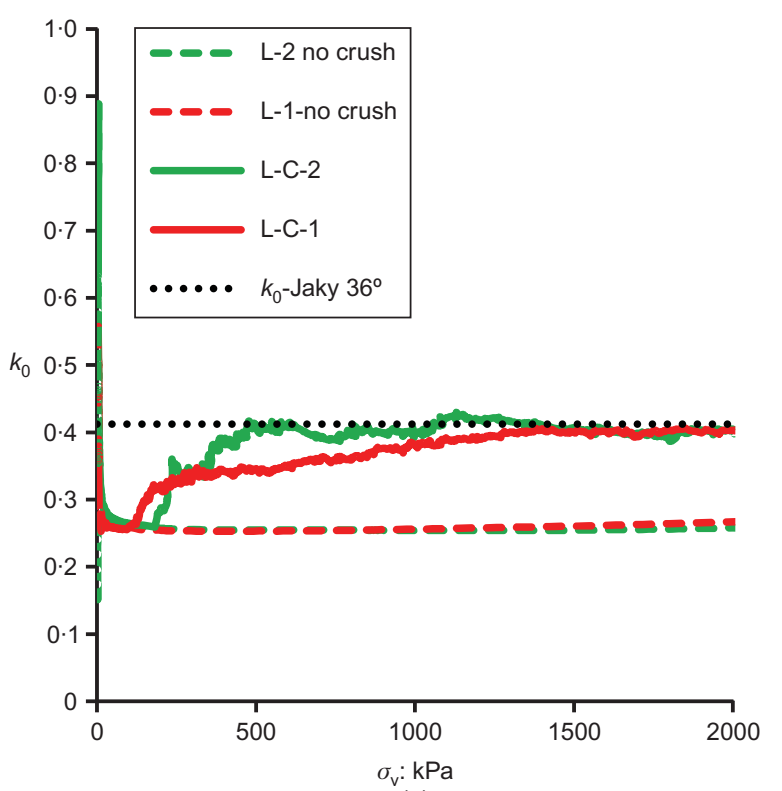

(a)

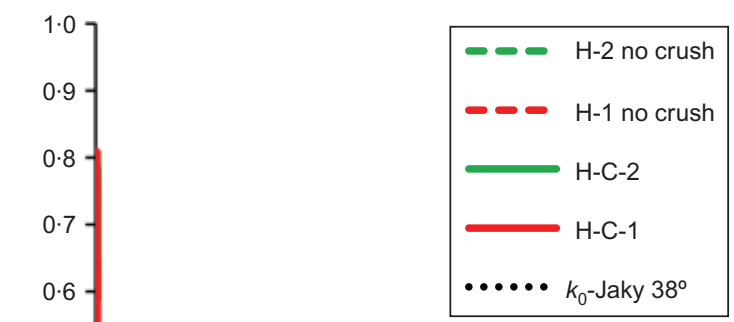

$k_{0} \quad 0.5$

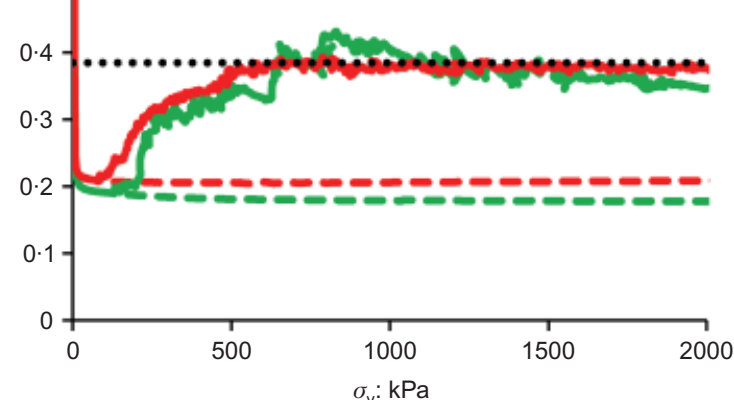

(c)

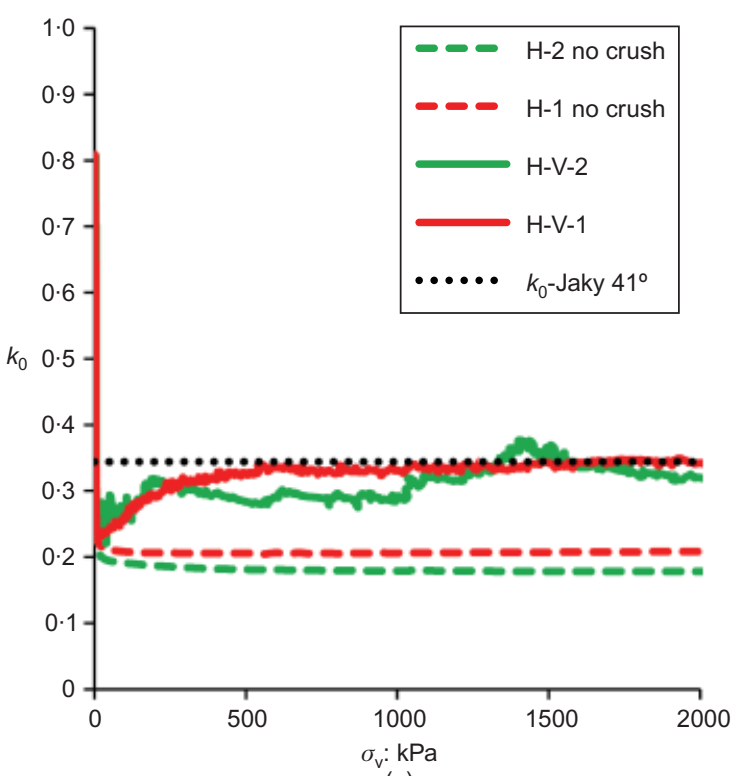

(e)

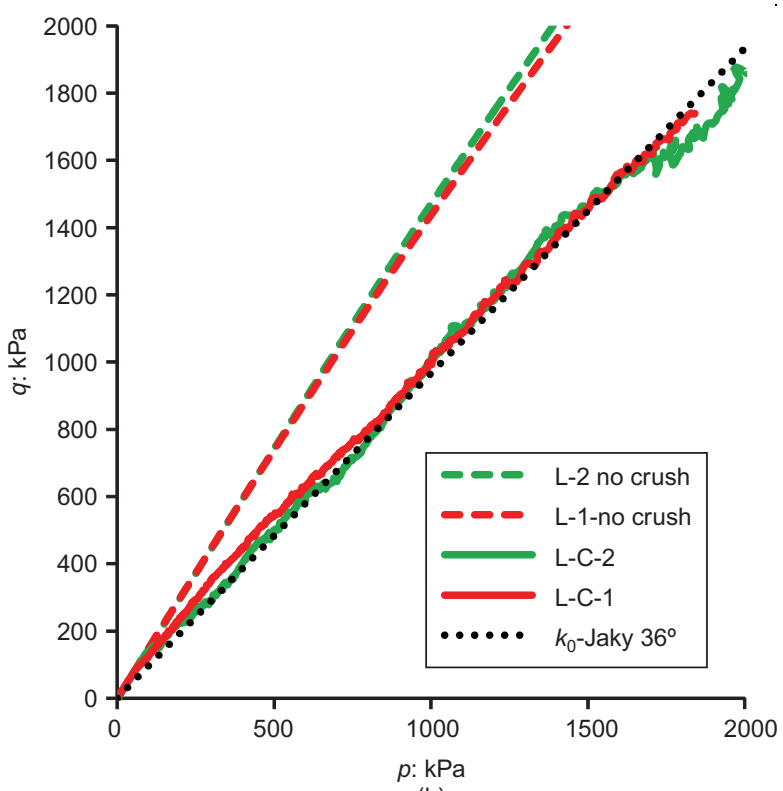

(b)

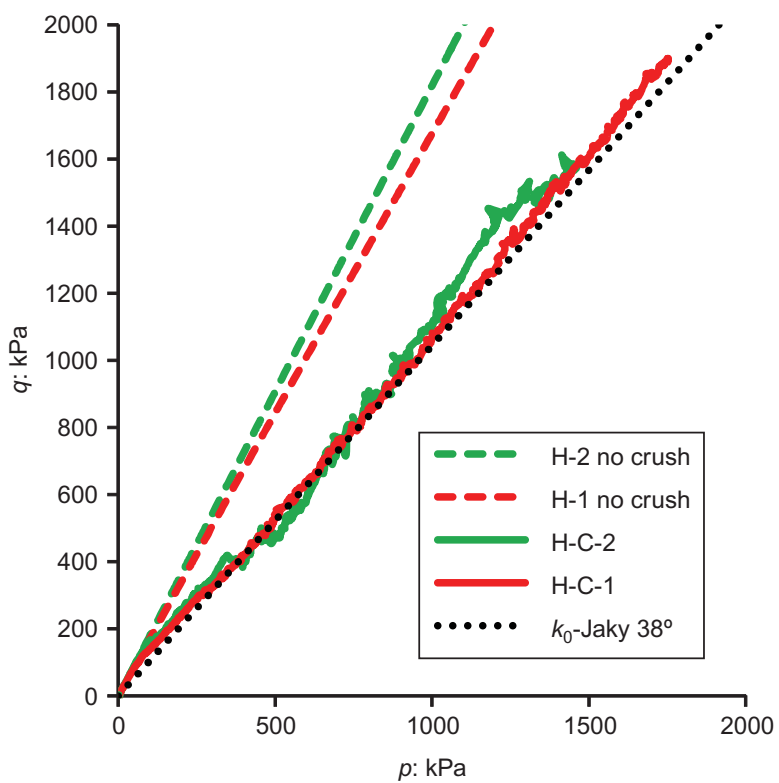

(d)

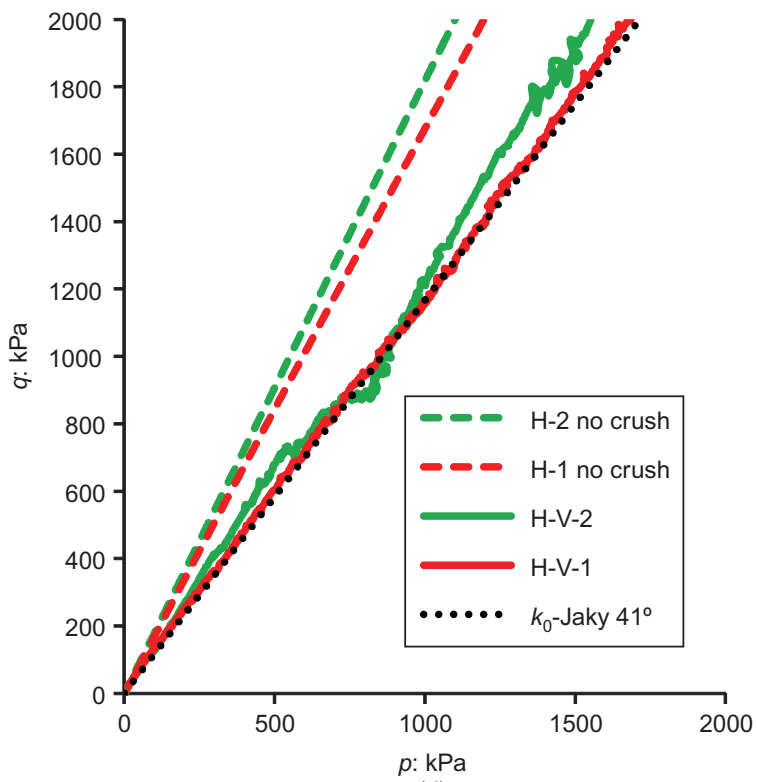

(d)

Fig. 11. Scale 1 and scale 2 model results: (a), (c) and (e) lateral pressure coefficient evolution with vertical stress; (b), (d) and (f) corresponding stress paths in $q-p$ plane for DEM simulations of one-dimensional compression of petroleum coke 


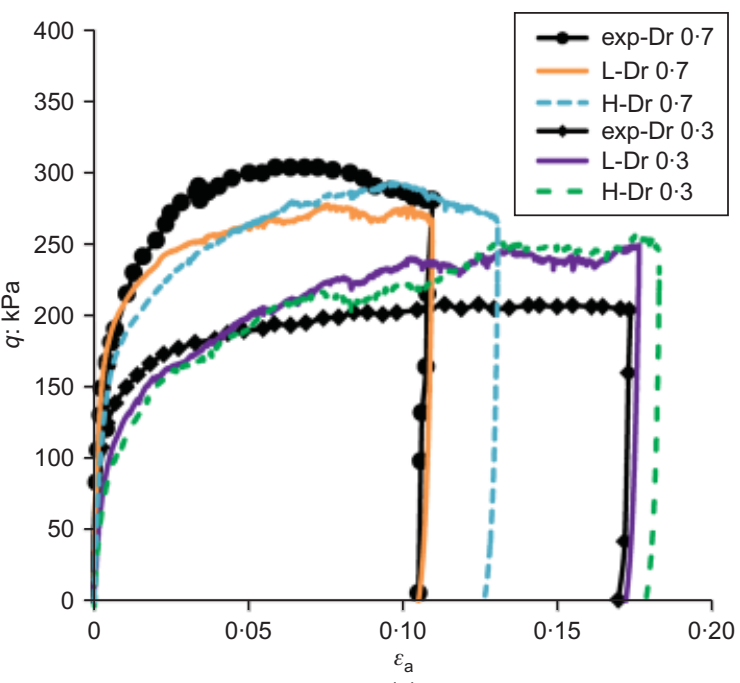

(a)

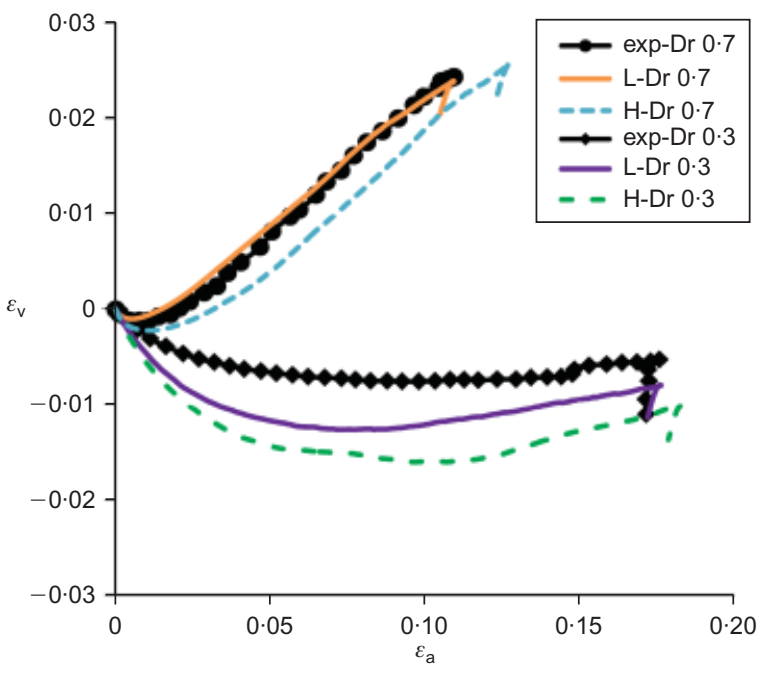

(b)

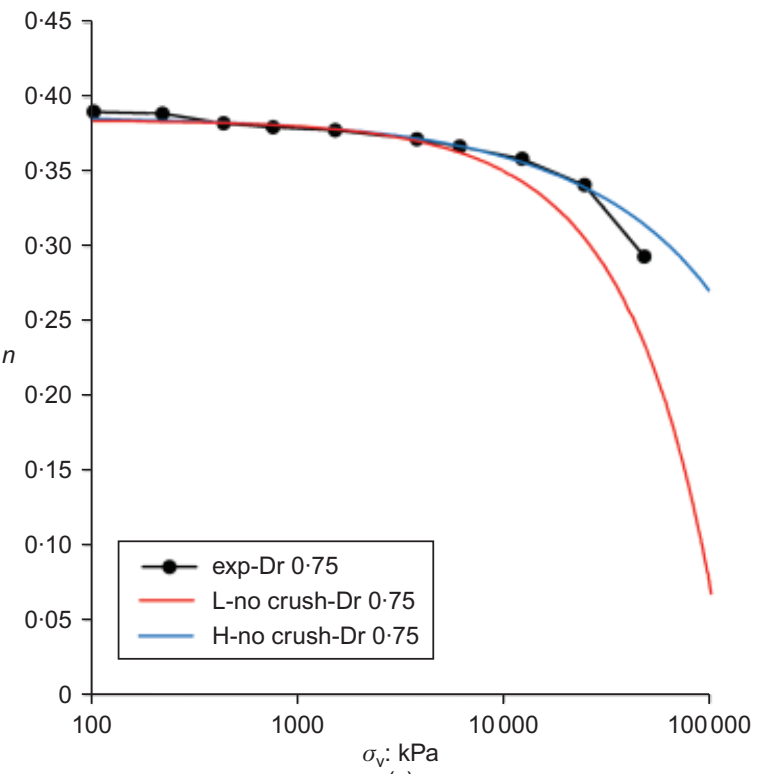

(c)

Fig. 12. DEM simulation of drained triaxial compression test (cell pressure $100 \mathrm{kPa}$ ): (a) deviatoric stress plotted against axial strain; (b) volumetric strain plotted against axial strain; (c) oedometric compression of Fontainebleau sand without considering particle breakage. The $L$ and $H$ symbols in the key correspond to 'linear' and 'Hertzian' contact models, respectively point was used to adjust $\sigma_{\lim , 0}$. At the larger stress levels (above $50 \mathrm{MPa}$ ) the experiment showed a clear stiffening behaviour; to capture better this behaviour and based on the sensitivity analysis described in Fig. 7 the comminution limit was set to $0.55 d_{50}$.

Only Hertzian contact models will be considered here, since the poor performance of the linear contact model for strong materials was already illustrated in the previous section. In particular, in Fig. 15 the simulation results obtained using constant and variable contact angle failure criteria are compared with the experimental results in a $n-\sigma_{\mathrm{v}}$ plane and a $\varepsilon_{\mathrm{v}}-\sigma_{\mathrm{v}}$ plane. The latter was used to better compare the results as it is difficult to achieve the same initial porosity in the numerical models. It can be appreciated how the Hertzian contact area with variable contact angle $(\mathrm{H}-\mathrm{V})$ tests shows a better approximation to the experimental results than the tests with constant contact area (H-C). In Fig. 16 the evolution of GSD is compared with the experimental data. Here too the $\mathrm{H}-\mathrm{V}$ runs seem to perform better than the $\mathrm{H}-\mathrm{C}$ simulations. Finally, in Fig. 17 the evolution of $k_{0}$ with vertical load is presented, as for the other two materials. It is again noted that simulation results with a scale factor of 2 gave very similar results to those with a factor of 1 .

\section{DISCUSSION}

The modelling approach described here can be easily generalised to accommodate different contact area or contact stiffness models. Other particle material failure criteria (e.g. Mohr-Coulomb or Hoek-Brown), might be used, but the analytical work of Russell \& Muir Wood (2009) would then need to be replicated. Variable internal porosity can be also incorporated, as illustrated by Ciantia et al. (2015).

How best to constrain the choice of a practical comminution limit is also a subject worthy of more detailed investigations. As illustrated in Fig. 15 this is particularly important for modelling advanced breakage states, where the mass not represented in the mechanical model is larger. The same figure also illustrates that, despite its limitations, the proposed approach is accurate up to stresses that double those attainable when mass conservation is strictly enforced (as was the case in the simulation by McDowell \& de Bono, 2013). This useful range extension is also enabled by the proposed procedure for post-processing GSD. That postprocessing works best if there is a good overlap of fragment sizes and original particle size.

In previous sections, the authors have highlighted the performance of the models from the point of view of their ability to reproduce the experimental observations. However, particularly if the final goal is to apply the calibrated discrete materials to simulate larger scale problems, it is also pertinent to discuss model efficiency. In this context, efficiency is closely represented by model runtime, since all the simulations were performed using the same hardware (Intel $\left(\right.$ Core $^{\mathrm{TM}}$ i7 $-3770 \mathrm{CPU}$ at $3.40 \mathrm{GHz}$ with $8.00 \mathrm{~GB}$ of Ram). Table 4 thus summarises several outcomes of the model: model runtime, initial and final particle number and crush events. The table also includes a number, 'Excluded particles', that roughly estimates the number of particles that would have been necessary to preserve mass. It is computed apportioning all the mass lost as particles with diameter half the size of the smallest particle obtained by the crushing event.

As expected, the number of crushing events is relatively higher for the weak material than for the strong ones. For the petroleum coke there were far more crushing events than initial particles, whereas for the strong sands the number of crushing events remained well below that of initial particles. 


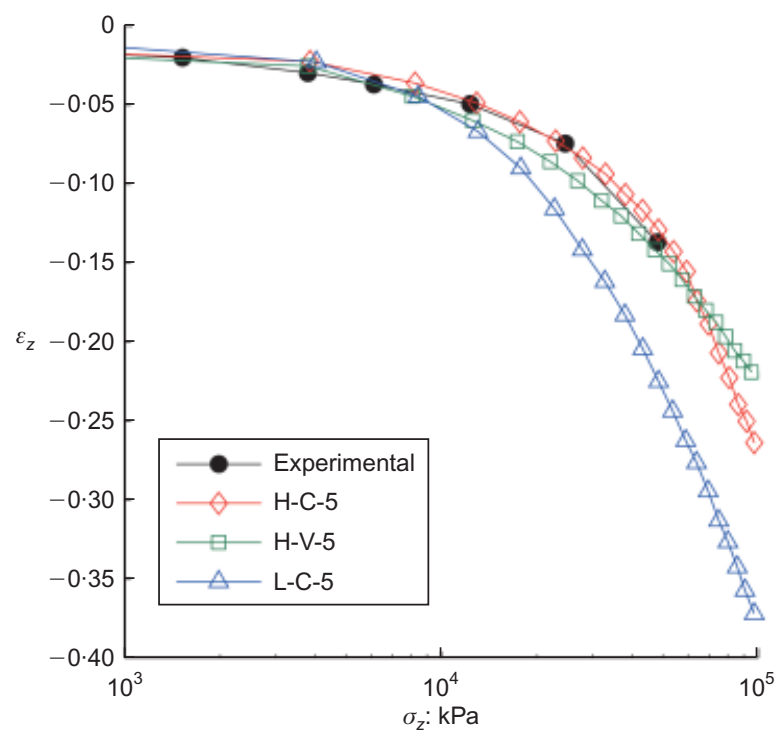

(a)

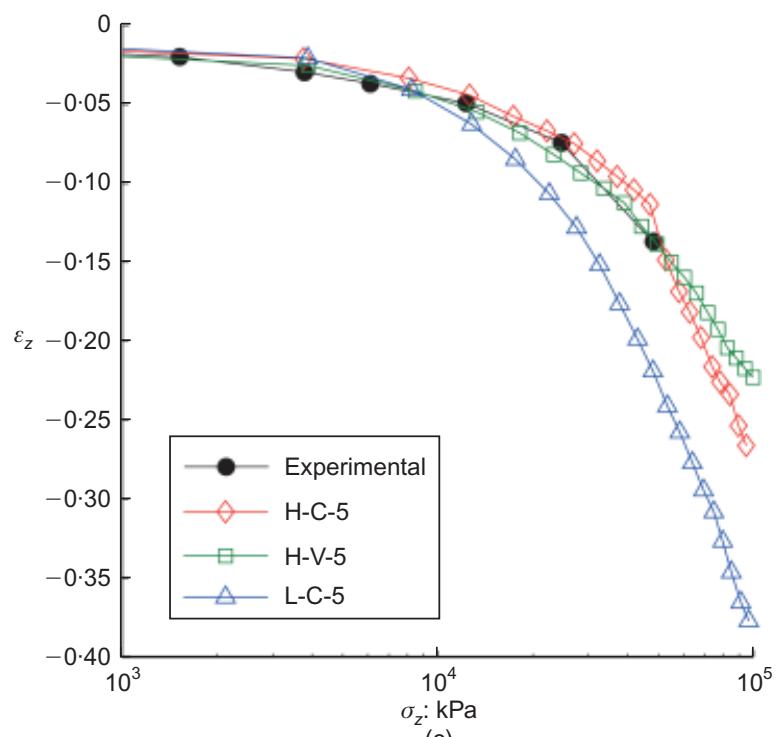

(c)

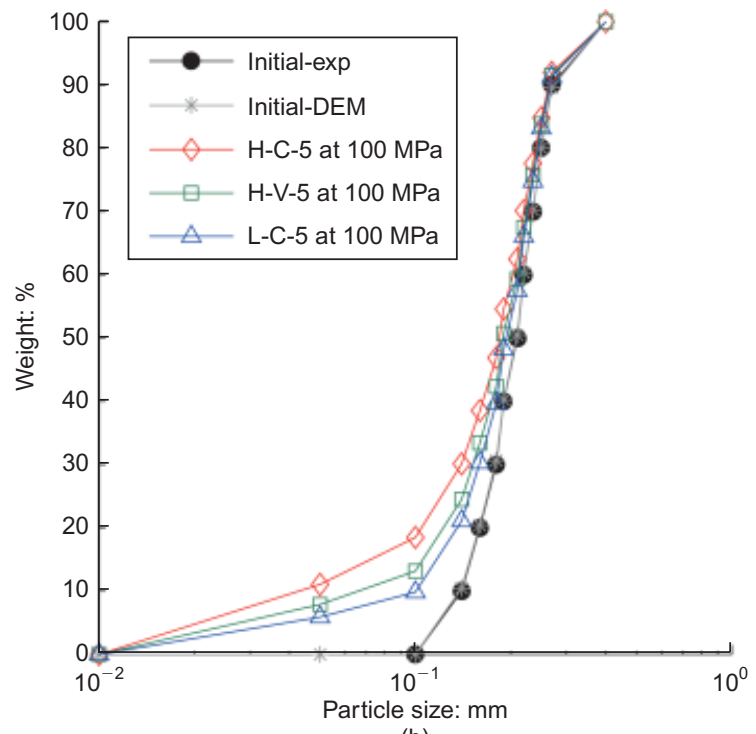

(b)

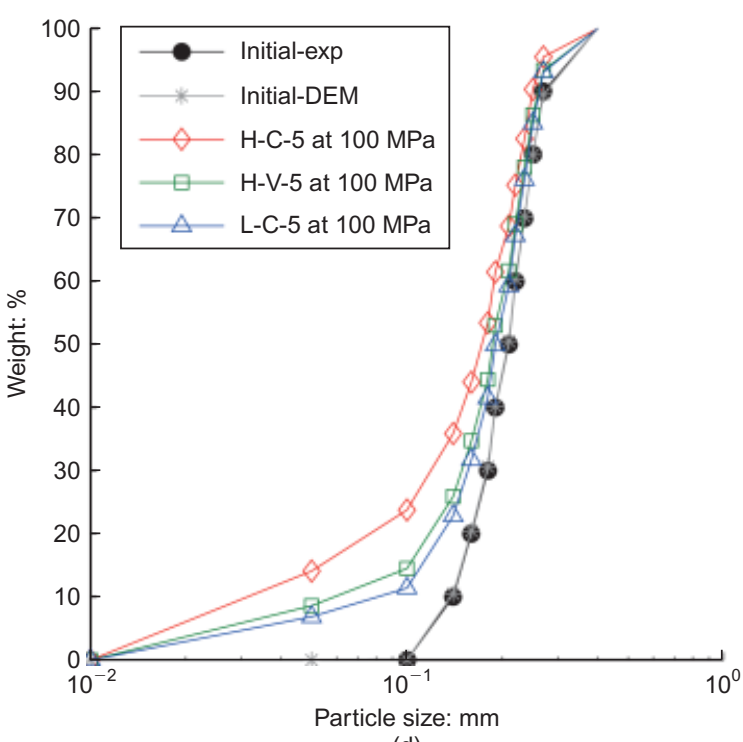

(d)

Fig. 13. DEM simulation of oedometric compression showing the effect of particle breakage on (a) NCL and (b) GSD evolution for scale 5 linear (L) and Hertzian (H) contact models; (c) and (d) show the same results for scale 10 simulations

Also, as expected, a major factor affecting model efficiency seems to be the number of particles at the beginning of the simulation. Since this number scales with the cube of the linear scaling factor, doubling the scaling factor results in runs that are typically around six times faster.

In this respect, it should be finally noted that the computed number of excluded particles is, roughly, around 15 times that of the final number of particles in the simulation. As was already shown in Fig. 7(c), this clearly implies that the choice of the particle spawning procedure has a very important bearing on the computational efficiency of the model. The compounded effect of scaling particle size and limiting spawning fragments in these simulations is a factor close to 100 in simulation runtime (Fig. 18).

Contact models do also have an influence on runtime, but this is second order and affected by code-specific issues. For instance, the variation of stiffness with particle size (equation (14)) is intrinsic to the Hertzian contact model while it had to be coded separately by means of FISH (short for FLACish, a PFC built-in programming language) functions for the linear contact model. FISH functions result in communication overheads that might be avoided if the contact model source code is directly modified.

\section{CONCLUSIONS}

A multigenerational DEM approach has been used to simulate 1D compression of soils of very different grain strength. Linear and Hertzian contact models are compared with experimental data from the literature, in terms of NCLs, GSD evolution, lateral pressure coefficient, $k_{0}$ and computational burden. For highly crushable materials such as petroleum coke (charcoal) the two contact models give very similar results in terms of slope of NCL, GSD evolution and evolution of $k_{0}$ with vertical stress. On the other hand, when strong grained materials are considered, the linear contact model does not adequately reproduce crushing and all its mechanical consequences.

Besides having a rigorous basis, the breakage model introduced allows for a clear separation between bulk and contact properties that allow separate refinement of these two aspects and flexibility in calibration, for instance using single particle compression tests. The use of upscaled models in calibration makes the calibration process quite efficient.

The spawning procedure advocated results in lost mass during the simulation; however, that loss does not seem to affect significantly the ability of the models to match 


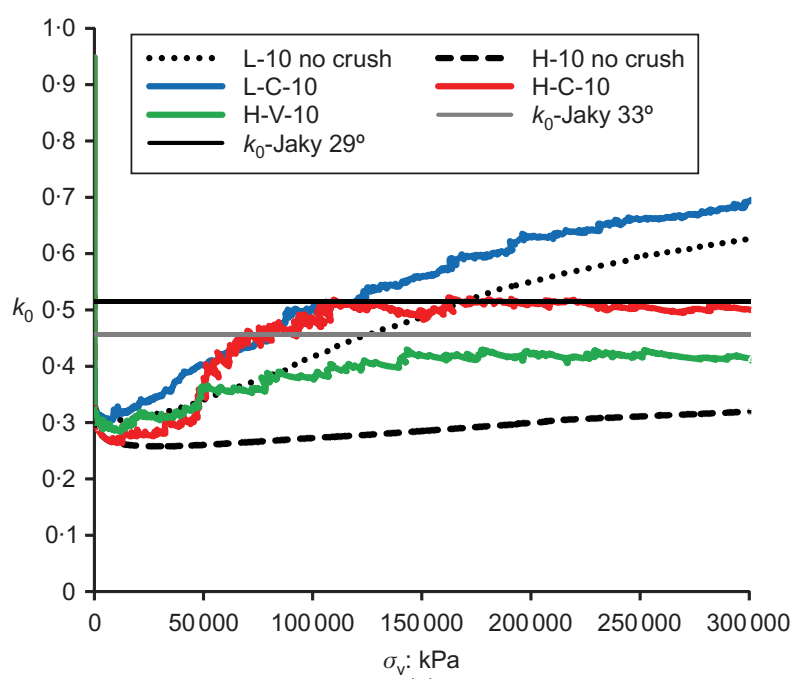

(a)

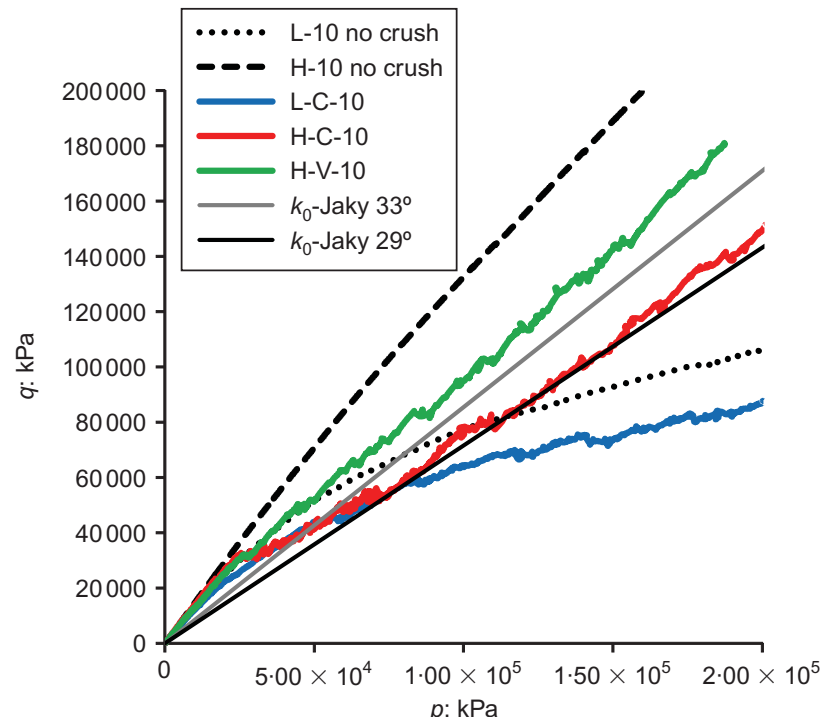

(c)

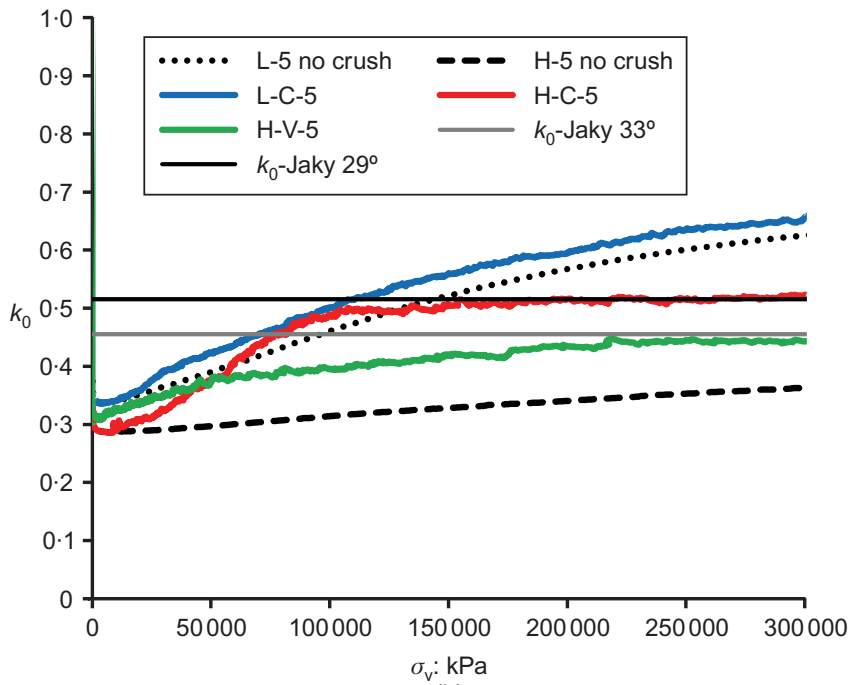

(b)

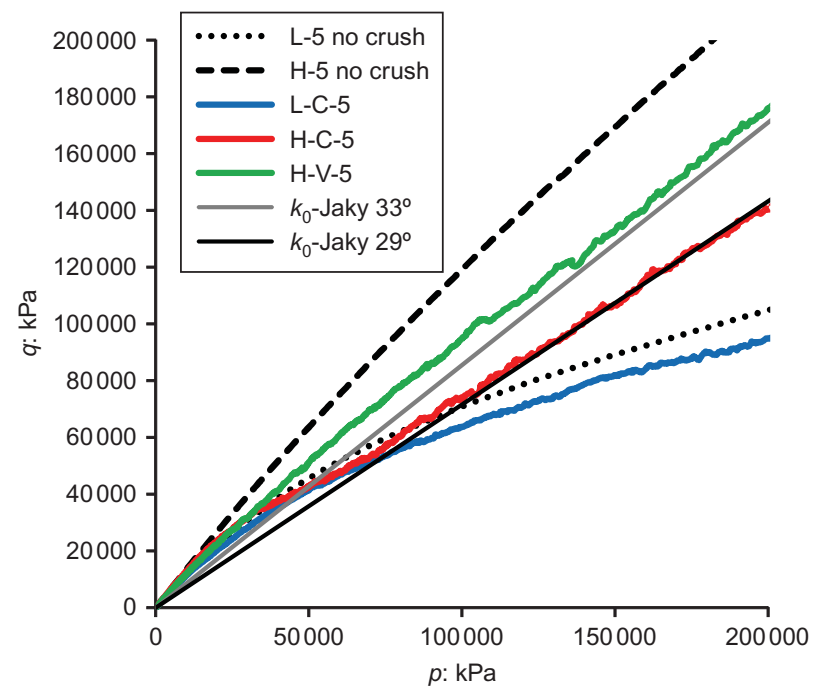

(d)

Fig. 14. Scale 10 and scale 5 DEM simulations results of: (a), (b) lateral pressure coefficient evolution with vertical stress; (c), (d) corresponding stress paths in $q-p$ plane for DEM simulations of one-dimensional compression of Fontainebleau sand

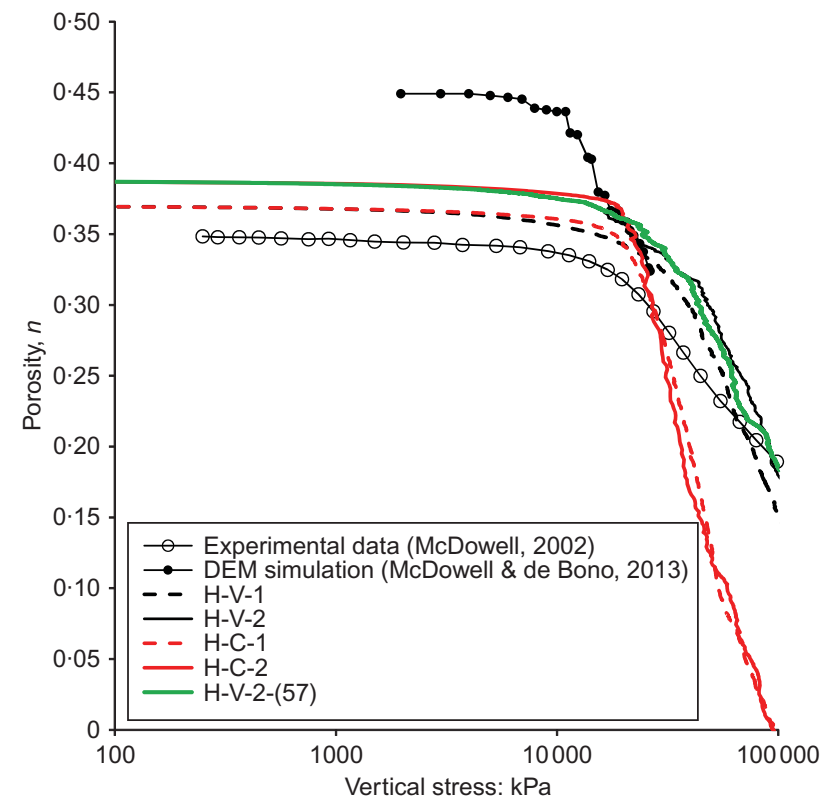

(a)

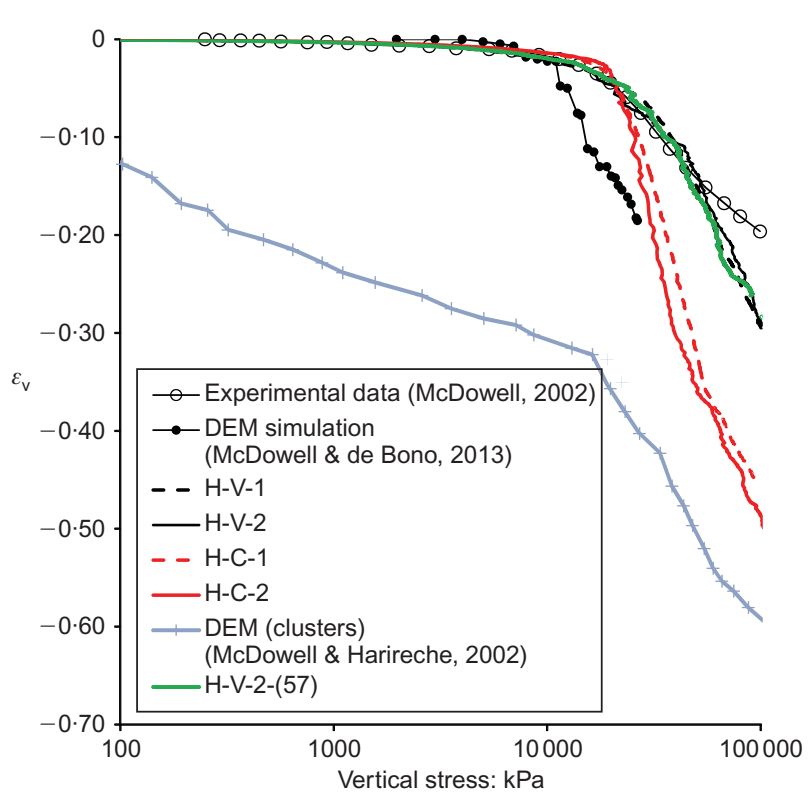

(b)

Fig. 15. Comparison of DEM simulations and experimental data of 1D compression tests for silica sand in (a) $n-\sigma_{\mathrm{v}}$ plane and (b) $\varepsilon_{\mathrm{v}}-\sigma_{\mathrm{v}}$ plane 


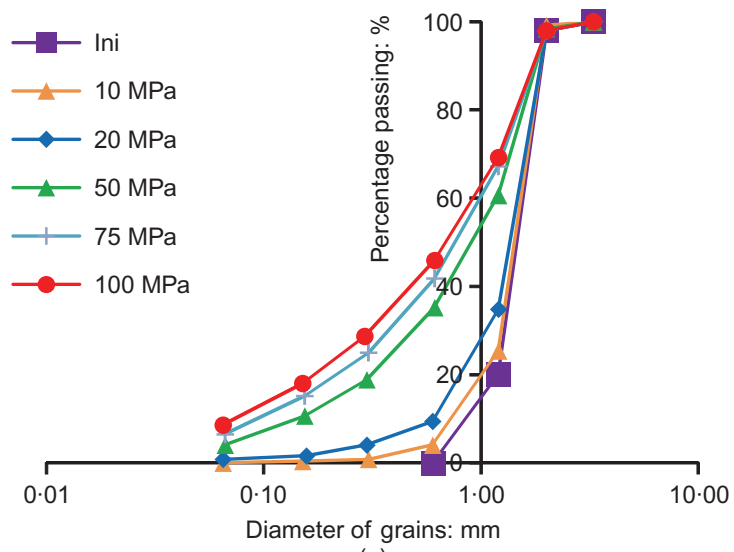

(a)
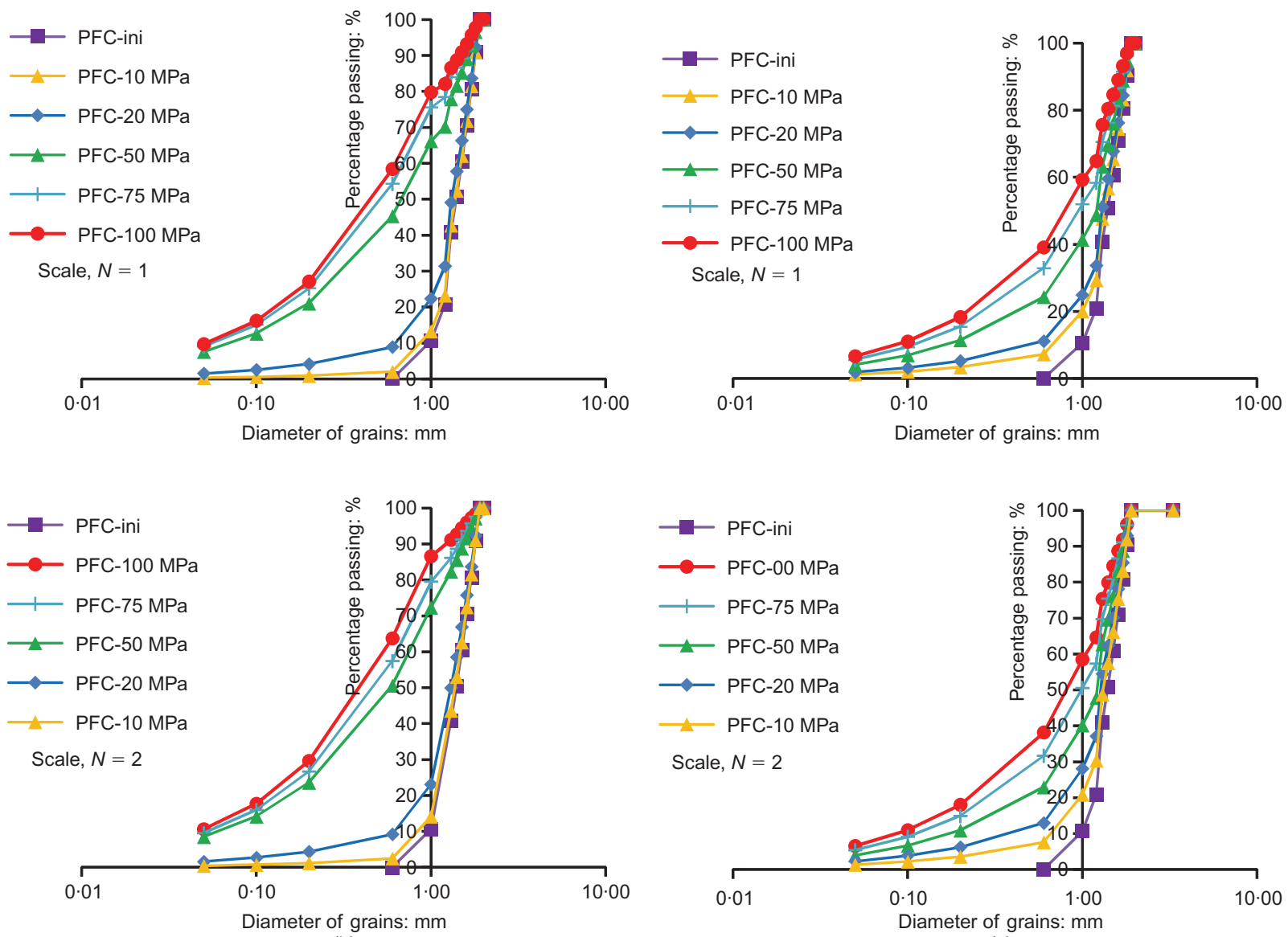

(b)

(c)

Fig. 16. GSD evolution for: (a) experimental result; (b) H-C-1 and H-C-2; (c) H-V-1 and H-V-2

the experimentally observed macroscopic response. This model feature takes advantage of the generally highly redundant and skewed mechanics of force transmission through discrete materials. This work also substantiates the computational efficiency of the upscaling rules proposed. It is shown that calculation time can be reduced considerably with little difference in terms of mechanical behaviour and GSD evolution. The proposed procedures can be considered as a springboard for future large-scale simulations.

\section{ACKNOWLEDGEMENTS}

This work has been supported by the Ministry of Science and Innovation of Spain through the research grant BIA2011-27217. Matteo O. Ciantia wishes to thank Dr
Luigi Pellegrini for many helpful discussions concerning the Apollonian packing problem.

\section{APPENDIX. PARTICLE SPAWNING PROCEDURE}

DETAILS

By means of a FISH function, during the numerical analysis, a loop across all particles checks if any of the contacts transmits a force that exceeds the limit condition. If the failure criteria are violated, the unit vector $n$ of components, $n_{x} n_{y} n_{z}$, that identifies the direction of the force is temporary saved. At this point the crushed configuration in its reference disposition is created replacing the original sphere. Subsequently, using the coordinates of the centres of the daughter particles in the reference system (Table 5), the configuration is subject to two subsequent rotations; one with respect to the $y^{\prime}$ axis and the other with respect to the $x^{\prime}$ axis such that the vertical axis in the reference configuration is parallel to the direction of the contact force. 


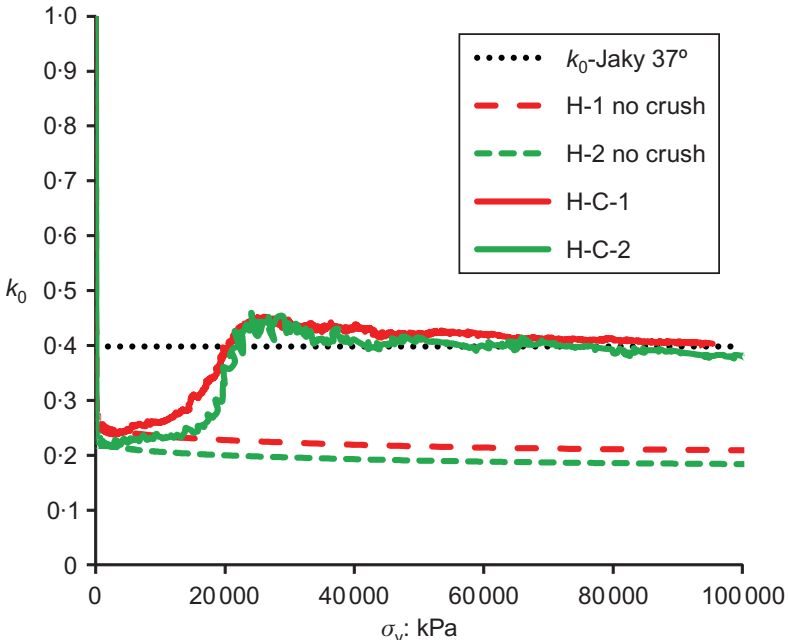

(a)

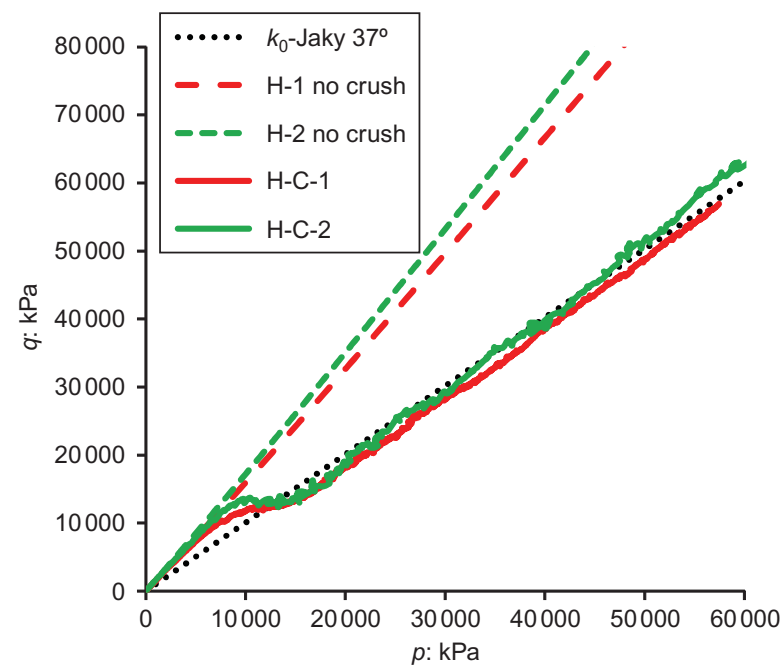

(c)

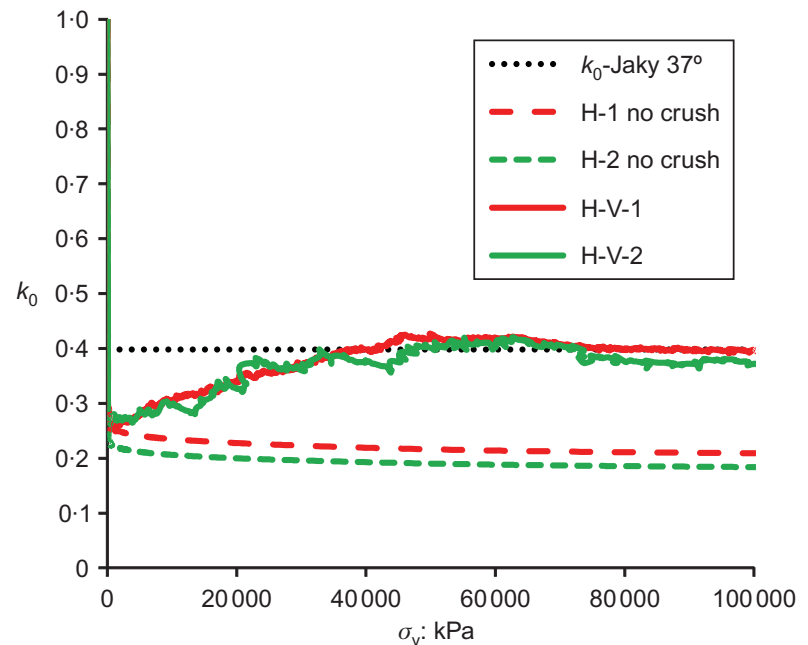

(b)

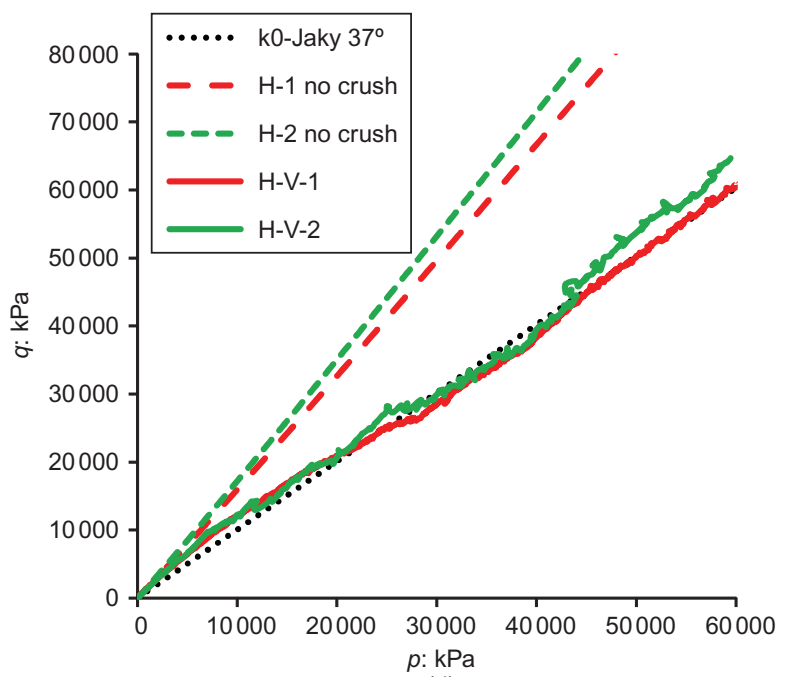

(d)

Fig. 17. (a), (b) Lateral pressure coefficient evolution with vertical stress and (c), (d) corresponding stress paths in $q-p$ plane for scale 1 and scale 2 DEM simulations of one-dimensional compression of silica sand

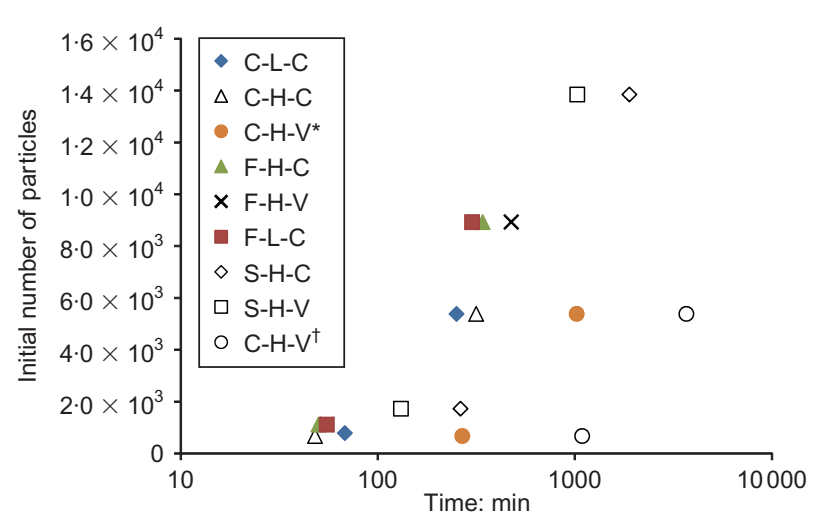

(a)

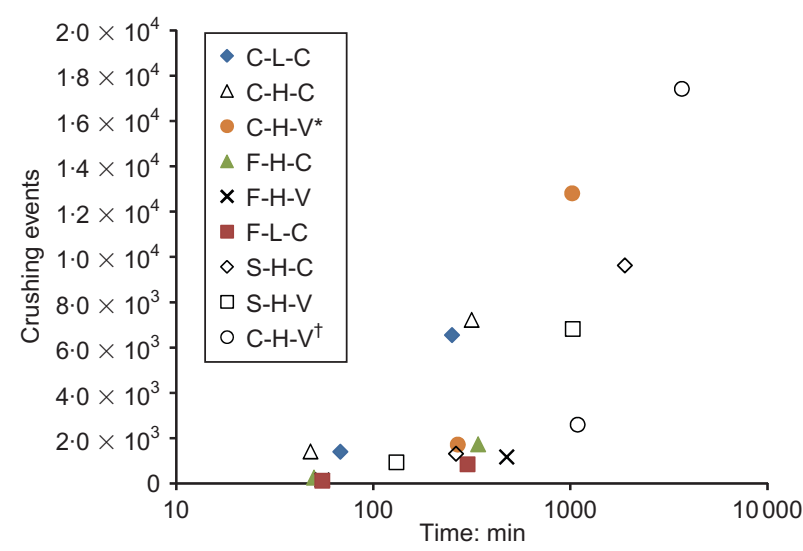

(b)

Fig. 18. Simulation time with initial number of (a) particles and (b) crushing events

\section{NOTATION}

$A_{F}$ contact area

$D_{1}, D_{2}$ diameters of the two spheres in contact

$d_{\text {limit }}$ comminution limit

$d_{\max }$ maximum particle size

$d_{\min }$ minimum observed particle size

$d_{0}$ particle diameter

$d_{0}$ reference diameter (chosen as $2 \mathrm{~mm}$ )
$F$ magnitude of normal contact force

$F_{\text {lim }}$ magnitude of limit normal contact force

$G$ shear modulus

$i$ step of the calculation

$K_{\text {eff }}, \alpha_{\mathrm{S}}$ material constants

$k_{\mathrm{N}}$ normal contact stiffness

$k_{\mathrm{S}}$ tangential contact stiffness

$k_{0} \quad$ lateral pressure coefficient 
Table 5. Fourteen-ball configuration where $R$ represents the radius of the 'mother ball' while $r$ stands for the radius of the daughter particles

\begin{tabular}{l|c|c|c|c}
\hline Ball ID & $r / R$ & $x^{\prime} / R$ & $y^{\prime} / R$ & $z^{\prime} / R$ \\
\hline 1 & $0 \cdot 4641$ & 0 & $0 \cdot 5359$ & 0 \\
2 & $0 \cdot 4641$ & $-0 \cdot 4641$ & $-0 \cdot 2679$ & 0 \\
3 & $0 \cdot 4641$ & $0 \cdot 4641$ & $-0 \cdot 2679$ & 0 \\
4 & $0 \cdot 2240$ & $-0 \cdot 6720$ & $0 \cdot 3880$ & 0 \\
5 & $0 \cdot 2240$ & $0 \cdot 6720$ & $0 \cdot 3880$ & 0 \\
6 & $0 \cdot 2240$ & $0 \cdot 0000$ & -0.7760 & 0 \\
7 & $0 \cdot 3659$ & 0 & 0 & 0.6339 \\
8 & $0 \cdot 3659$ & 0 & 0 & -0.6339 \\
9 & $0 \cdot 2573$ & 0 & $-0 \cdot 5942$ & 0.4456 \\
10 & $0 \cdot 2573$ & $0 \cdot 5146$ & $0 \cdot 2971$ & 0.4456 \\
11 & $0 \cdot 2573$ & $-0 \cdot 5146$ & $0 \cdot 2971$ & 0.4456 \\
12 & $0 \cdot 2573$ & 0 & -0.5942 & -0.4456 \\
13 & $0 \cdot 2573$ & $0 \cdot 5146$ & $0 \cdot 2971$ & -0.4456 \\
14 & $0 \cdot 2573$ & $-0 \cdot 5146$ & $0 \cdot 2971$ & -0.4456 \\
\hline
\end{tabular}

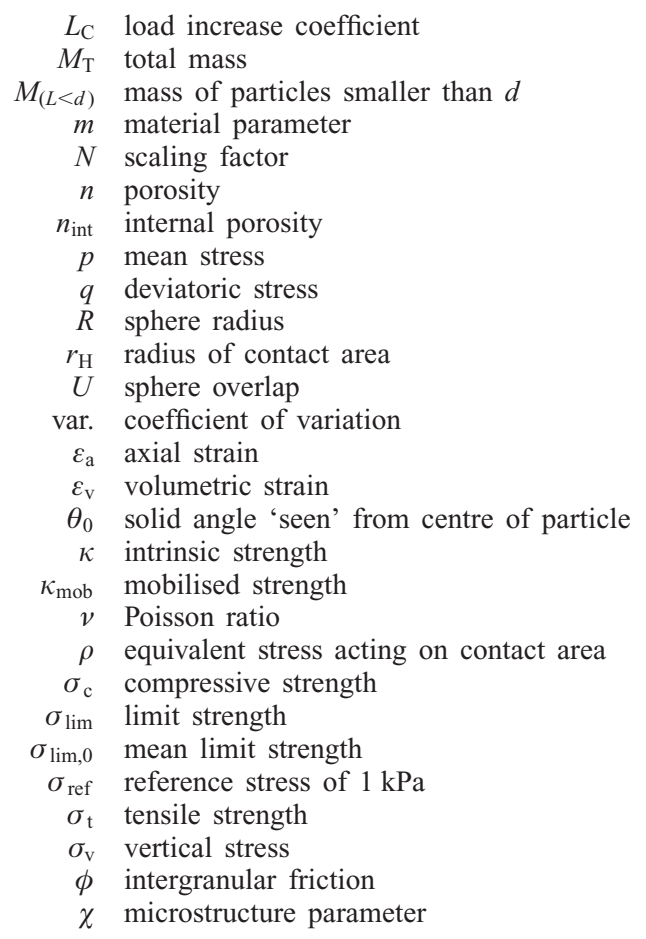

\section{REFERENCES}

Alonso, E. E., Olivella, S. \& Pinyol, N. P. (2005). A review of Beliche dam. Géotechnique 55, No. 4, 267-285, http://dx.doi. org/10.1680/geot.2005.55.4.267.

Alonso, E. E., Tapias, M. \& Gili, J. (2012). Scale effects and rockfill behaviour. Géotechnique Lett. 2, No. 3, 161-166.

Altuhafi, F. N. \& Coop, M. R. (2011). Changes to particle characteristics associated with the compression of sands. Géotechnique 61, No. 6, 459-471, http://dx.doi.org/10.1680/geot.9.P.114.

Arroyo, M., Butlanska, J., Gens, A., Calvetti, F. \& Jamiolkowski, M. (2011). Cone penetration tests in a virtual calibration chamber. Géotechnique 61, No. 6, 525-531, http://dx.doi.org/10.1680/ geot.9.P.067.

Astrom, J. A. \& Herrmann, H. J. (1998). Fragmentation of grains in a two-dimensional packing. Eur. Phys. J. B 5, No. 3, 551-554.

Ben-Nun, O. \& Einav, I. (2008). A refined DEM study of grain size reduction in uniaxial compression. Proceedings of the 12th international conference of the international association for computer methods and advances in geomechanics (IACMAG), Goa, India, pp. 702-708.

Ben-Nun, O. \& Einav, I. (2010). The role of self-organization during confined comminution of granular materials. Phil. Trans. R. Soc. A 368, No. 1910, 231-247.

Ben-Nun, O., Einav, I. \& Tordesillas, A. (2010). Force attractor in confined comminution of granular materials. Phys. Rev. Lett. 104, No. 10, 108001.

Bolton, M. D., Nakata, Y. \& Cheng, Y. P. (2008). Micro-and macromechanical behaviour of DEM crushable materials. Géotechnique 58, No. 6, 471-480, http://dx.doi.org/10.1680/ geot.2008.58.6.471.

Borkovec, M., De Paris, W. \& Peikert, R. (1994). The fractal dimension of the Apollonian sphere packing. Fractals 2, No. 04, 521-526.

Brosh, T., Kalman, H. \& Levy, A. (2011). Fragments spawning and interaction models for DEM breakage simulation. Granular Matter 13, No. 6, 765-776.

Bruchmüller, J., Van Wachem, B. G. M., Gua, S. \& Luo, K. H. (2011). Modelling discrete fragmentation of brittle particles. Powder Technol. 208, No. 3, 731-739.

Brzesowsky, R. H., Spiers, C. J., Peach, C. J. \& Hangx, S. J. T. (2011). Failure behavior of single sand grains: theory versus experiment. J. Geophys. Res.: Solid Earth (1978-2012) 116, B06205.

Butlanska, J., Arroyo, M., Gens, A. \& O’Sullivan, C. (2013). Multiscale analysis of CPT in a virtual calibration chamber. Can. Geotech. J. 51, No. 1, 51-66.

Cheng, Y. P., Nakata, Y. \& Bolton, M. D. (2003). Discrete element simulation of crushable soil. Géotechnique 53, No. 7, 633-641, http://dx.doi.org/10.1680/geot.2003.53.7.633.

Cheung, L. Y. G., O'Sullivan, C. \& Coop, M. R. (2013). Discrete element method simulations of analogue reservoir sandstones. Int. J. Rock Mech. Mining Sci. 63, 93-103.

Christensen, R. M. (2000). Yield functions, damage states, and intrinsic strength. Math. Mech. Solids 5, No. 3, 285-300.

Ciantia, M., Arroyo, M., Gens, A. \& Calvetti, F. (2014). Particle failure in DEM models of crushable soil response. In Numerical methods in geotechnical engineering, NUMGE 2014 (eds M. A. Hicks, R. B. J. Brinkgreve and A. Rohe), pp. 345-350. Leiden, the Netherlands: CRC Press/Balkema.

Ciantia, M., Arroyo, M., Butlanska, J. \& Gens, A. (2015). DEM modelling of a double-porosity crushable granular material. In Geomechanics from micro to macro (eds K. Soga, K. Kumar, G. Biscontin and M. Kuo), pp. 269-274. Leiden, the Netherlands: CRC Press/Balkema.

Cil, M. B. \& Alshibli, K. A. (2012). 3D assessment of fracture of sand particles using descrete element method. Géotechnique Lett. 2, No. 3, 161-166.

Couroyer, C., Ning, Z. \& Ghadiri, M. (2000). Distinct element analysis of bulk crushing: effect of particle properties and loading rate. Powder Technol. 109, No. 1, 241-254.

Cundall, P. A. (1987). Distinct element models of rock and soil structure. In Analytical and computational methods in engineering rock mechanics (ed. E. T. Brown), ch. 4, pp. 129-163. London, UK: Allen \& Unwin.

Cundall, P. \& Strack, O. (1979). A discrete numerical model for granular assemblies. Géotechnique 29, No. 1, 47-65, http:// dx.doi.org/10.1680/geot.1979.29.1.47.

Díaz-Terán, J., Nevskaia, D. M., López-Peinado, A. J. \& Jerez, A. (2001). Porosity and adsorption properties of an activated charcoal. Colloids and Surfaces A: Physicochem. Engng Aspects 187-188, 167-175.

Einav, I. (2007). Breakage mechanics - part I: theory. J. Mech. Phys. Solids 55, No. 6, 1274-1297.

Gabrieli, F., Cola, S. \& Calvetti, F. (2009). Use of an up-scaled DEM model for analysing the behaviour of a shallow foundation on a model slope. Geomech. Geoengng: Int. J. 4, No. 2, 109122.

Goodman, R. E. (1989). Introduction to rock mechanics, 2nd edn. New York, NY, USA: Wiley.

Itasca (2008). PFC3D Particle flow code in three dimensions: Software manual. Minneapolis, MN, USA: Itasca Consulting Group.

Jansen, U. \& Stoyan, D. (2000). On the validity of the Weibull failure model for brittle particles. Granular Matter 2, No. 4, $165-170$.

Kikumoto, M., Wood, D. M. \& Russell, A. (2010). Particle crushing and deformation behaviour. Soils Found. 50, No. 4, 547-563. 
Lim, W. L., McDowell, G. R. \& Collop, A. C. (2004). The application of Weibull statistics to the strength of railway ballast. Granular Matter 6, No. 4, 229-237.

Lobo-Guerrero, S. \& Vallejo, L. E. (2005). Crushing a weak granular material: experimental numerical analyses. Géotechnique 55, No. 3, 245-249, http://dx.doi.org/10.1680/ geot.2005.55.3.245.

Lobo-Guerrero, S. \& Vallejo, L. E. (2006). Application of Weibull statistics to the tensile strength of rock aggregates. J. Geotech. Geoenviron. Engng 132, No. 6, 786-790.

Marketos, G. \& Bolton, M. D. (2009). Compaction bands simulated in discrete element models. J. Struct. Geol. 31, No. 5, 479-490.

Marketos, G. \& Bolton, M. D. (2010). Flat boundaries and their effect on sand testing. Int. J. Numer. Analyt. Methods Geomech. 34, No. 8, 821-837.

Mašín, D. (2012). Asymptotic behaviour of granular materials. Granular Matter 14, No. 6, 759-774.

McDowell, G. R. (2002). On the yielding and plastic compression of sand. Soils Found. 42, No. 1, 139-145.

McDowell, G. R. \& Amon, A. (2000). The application of Weibull statistics to the fracture of soil particles. Soils Found. 40, No. 5, 133-141.

McDowell, G. R. \& Bolton, M. D. (1998). On the micro mechanics of crushable aggregates. Géotechnique 48, No. 5, 667-679, http://dx.doi.org/10.1680/geot.1998.48.5.667.

McDowell, G. R. \& de Bono, J. P. (2013). On the micro mechanics of one-dimensional normal compression. Géotechnique 63, No. 11, 895-908, http://dx.doi.org/10.1680/geot.12.P.041.

McDowell, G. R. \& Harireche, O. (2002). Discrete element modelling of soil particle fracture. Géotechnique 52, No. 2, 131-135, http://dx.doi.org/10.1680/geot.2002.52.2.131.

McDowell, G. R., Bolton, M. D. \& Robertson, D. (1996). The fractal crushing of granular materials. J. Mech. Phys. Solids 44, No. 12, 2079-2101.

Mesri, G. \& Vardhanabhuti, B. (2009). Compression of granular materials. Can. Geotech. J. 46, No. 4, 369-392.

Minh, N. H. \& Cheng, Y. P. (2013). A DEM investigation of the effect of particle-size distribution on one-dimensional compression. Géotechnique 63, No. 1, 44-53, http://dx.doi.org/10.1680/ geot.10.P.058.

Nakata, Y., Hyodo, M., Hyde, A. F., Kato, Y. \& Murata, H. (2001). Microscopic particle crushing of sand subjected to high pressure one-dimensional compression. Soils Found. 41, No. 1, 69-82.

O'Sullivan, C. (2011). Particle-based discrete element modeling: A geomechanics perspective. Hoboken, NJ, USA: Taylor \& Francis.
Radjai, F., Jean, M., Moreau, J. J. \& Roux, S. (1996). Force distributions in dense two-dimensional granular systems. Phys. Rev. Lett. 77, No. 2, 274.

Russell, A. R. \& Muir Wood, D. (2009). Point load tests and strength measurments for brittle spheres. I. J. Rock Mech. Mining Sci. 46, No. 2, 272-280.

Russell, A. R., Muir Wood, D. \& Kikumoto, M. (2009). Crushing of particles in idealised granular assemblies. J. Mech. Phys. Solids 57, No. 8, 1293-1313.

Seif El Dine, B. (2007). Etude du comportement mécanique de sols grossiers à matrice. $\mathrm{PhD}$ thesis, Ecole Nationale des Ponts et Chaussées, Paris, France (in French).

Seif El Dine, B., Dupla, J. C., Frank, R., Canou, J. \& Kazan, Y. (2010). Mechanical characterization of matrix coarse-grained soils with a large-sized triaxial device. Can. Geotech. J. 47, No. 4, 425-438.

Thornton, C. \& Antony, S. J. (2000). Quasi-static shear deformation of a soft particle system. Powder Technol. 109, No. 1-3, 179191.

Török, J., Fazekas, S., Unger, T. \& Wolf, D. E. (2005). Relationship between particle size and normal force. In Powders and grains 2005 (eds R. García-Rojo, H. J. Herrmann and S. McNamara), pp. 1273-1277. Boca Raton, FL, USA: CRC Press.

Tsoungui, O., Vallet, D. \& Charmet, J.-C. (1999a). Numerical model of crushing of grains inside two-dimensional granular materials. Powder Technol. 105, No. 1-3, 190-198.

Tsoungui, O., Vallet, D., Charmet, J. C. \& Roux, S. (1999b). Size effects in single grain fragmentation. Granular Matter 2, No. 1, 19-27.

Turcotte, D. L. (1986). Fractals and fragmentation. J. Geophys. Res 91, No. B2, 1921-1926.

Utili, S. \& Nova, R. (2008). DEM analysis of bonded granular geomaterials. Int. J. Numer. Analyt. Methods Geomech. 32, No. 17, 1997-2031.

Weibull, W. (1951). A statistical distribution function of wide applicability. J. Appl. Mech. 18, 293-297.

Yang, Z. X., Jardine, R. J., Zhu, B. T., Foray, P. \& Tshua, H. C. (2010). Sand grain crushing and interface shearing during displacement pile installation in sand. Géotechnique 60, No. 6 , 469-482, http://dx.doi.org/10.1680/geot.2010.60.6.469.

Yashima, S., Kanda, Y. \& Sano, S. (1987). Relationship between particle size and fracture as estimated from single particle crushing. Powder Technol. 51, No. 3, 277-282.

Zhang, C., Nguyen, G. D. \& Einav, I. (2013). The end-bearing capacity of piles penetrating into crushable soils. Géotechnique 63, No. 5, 341-354, http://dx.doi.org/10.1680/geot.11.P.117. 